\title{
Numerical investigation of wing morphing capabilities applied to a Horten type swept wing geometry
}

Ashwin Vishwanathan

West Virginia University

Follow this and additional works at: https://researchrepository.wvu.edu/etd

\section{Recommended Citation}

Vishwanathan, Ashwin, "Numerical investigation of wing morphing capabilities applied to a Horten type swept wing geometry" (2007). Graduate Theses, Dissertations, and Problem Reports. 1816.

https://researchrepository.wvu.edu/etd/1816

This Thesis is protected by copyright and/or related rights. It has been brought to you by the The Research Repository @ WVU with permission from the rights-holder(s). You are free to use this Thesis in any way that is permitted by the copyright and related rights legislation that applies to your use. For other uses you must obtain permission from the rights-holder(s) directly, unless additional rights are indicated by a Creative Commons license in the record and/ or on the work itself. This Thesis has been accepted for inclusion in WVU Graduate Theses, Dissertations, and Problem Reports collection by an authorized administrator of The Research Repository @ WVU. For more information, please contact researchrepository@mail.wvu.edu. 
Numerical Investigation of Wing Morphing Capabilities Applied to a Horten Type Swept Wing Geometry

\author{
Ashwin Vishwanathan \\ Thesis submitted to \\ College of Engineering and Mineral Resources \\ at \\ West Virginia University \\ in partial fulfillment of the requirements for the degree of \\ Master of Science \\ in \\ Mechanical Engineering \\ Wade W. Huebsch, Ph.D., Chair \\ John M.Kuhlman, Ph.D \\ Garry Morris, Ph.D \\ Department of Mechanical and Aerospace Engineering \\ Morgantown, West Virginia \\ 2007
}

Keywords: Wing morphing, Computational Fluid Dynamics, CMARC, Fluent, Wing Twist. 


\title{
ABSTRACT \\ Numerical Investigation of Wing Morphing Capabilities Applied to a Horten Type Swept Wing Geometry
}

\author{
Ashwin Vishwanathan
}

The inspiration for this work has been derived from the work done by Lippisch, the Hortens, Northrop and largely by the flight of birds in nature. Swept-wing tailless aircraft have been in vogue since World War-II and have now taken on a new role in stealth warfare primarily due to their low radar signatures. They also exhibit a highly efficient aerodynamic configuration with low parasitic drag. However, conventional tailless aircraft suffer from a lack of proper control mechanisms and have thus been forced to compromise their efficiency for better control. This work done at WVU aims to introduce a morphing mechanism for better control of tailless aircraft ${ }^{1}$. This morphing mechanism will provide for variable twist capability of the wing and can theoretically provide better roll, pitch and yaw control for a tailless aircraft. This research is intended to give us a better understanding of the flow physics that are encountered during the various morphed stages of flight and compares them to conventional geometries. A three dimensional model of a conventional and morphed wing was simulated using an inviscid panel code method at various stages of flight, and the results were compared to actual wind tunnel data. The study looks at the coefficients of lift, induced drag and the various moments encountered. Preliminary studies indicate wing morphing as a suitable candidate for more efficient flight.

\footnotetext{
${ }^{1}$ This work was funded by NASA-Dryden flight research center
} 


\section{Acknowledgements}

To start with I wish to express my sincere gratitude to my advisor Dr. Wade Heubsch for giving me the opportunity to work on such a challenging and novel topic. To my committee members Dr. Kuhlman whose grasp of the subject I shall always strive to achieve, who taught me about "sensitive dependence on initial conditions" and introduce me to the wonderful world of fractals. To Dr. Morris, who made my trips to the aero lab the most enjoyable. A much needed thanks to one and all.

I'd like to thank my dearest colleague Mr. Richard Guiler for having helped me by being extremely patient to clear up all my questions, to have enjoyed all our fruitful conversations and for having instilled in me a sense of amazement towards aircrafts.

My parents to whom I owe everything, I am ever thankful for their perennial support and encouragement. My dearest sister and brother in law, thank you for all the moral support. My dear friends Jay, DJ, PSG, Shashi, Holly, Anand, Murali and CVK thank you. Lastly, to all my colleagues at CFD-AMP for making this a wonderful experience. 


\section{Contents}

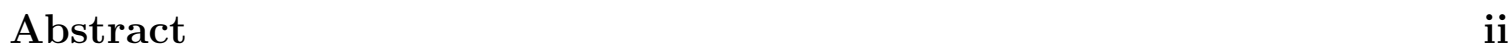

Acknowledgements iii

List of Tables vi vi

List of Figures vii

1 Introduction $\quad 1$

1.1 Background ........................... 1

1.2 Past research . . . . . . . . . . . . . . . . . . 1

1.3 Current work . . . . . . . . . . . . . . . . 2

2 Literature review 3

2.1 Wing Morphing . . . . . . . . . . . . . . . . 7

2.1.1 Smart Materials . . . . . . . . . . . . . . . 8

2.1.2 Flight Control using fluidic effectors . . . . . . . . . . . . 99 9

2.1.3 Structurally induced morph . . . . . . . . . . . . . . . . 9 9

2.2 Wing morphing at WVU . . . . . . . . . . . . . . . . 10

3 Geometry 12

3.1 Geometry details . . . . . . . . . . . . . . . . . . . 14

3.2 Mesh details . . . . . . . . . . . . . . . . . . . . . . . . . . . 17

3.3 Input conditions . . . . . . . . . . . . . . . . . . . . . . . 19

4 Panel codes and CMARC 20

4.1 CMARC input file . . . . . . . . . . . . . . . . . . . . . 22

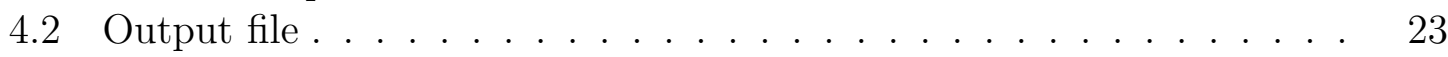

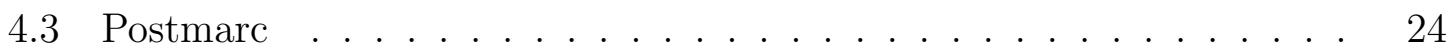

5 Results and Discussions $\quad 27$

5.1 CMARC results . . . . . . . . . . . . . . . . 27

5.1.1 Lift and drag characteristics . . . . . . . . . . . 27 
5.1 .2 Moment coefficients . . . . . . . . . . . . . . . . . . 34

5.1 .3 Wake region . . . . . . . . . . . . . . . 38

5.2 Comparison of Experimental and CMARC results . . . . . . . . . 41

6 Conclusions 49

References $\quad 51$

Appendices $\quad 53$

A CMARC input data 53 


\section{List of Tables}

2.1 Details of PUL-10 $[4] \ldots \ldots \ldots \ldots \ldots$. . . . . . . . . . . 7

3.1 Geometrical details of the wing . . . . . . . . . . . . . . 15

3.2 Control postions and their angle of twists . . . . . . . . . . . 16

4.1 Performance prediction from CMARC for a NACA 0010 wing . . . . 25

5.1 Percent increase in $C_{L}$ 's of morphed wing compared to conventional wing at $7^{\circ}$ angle of attack . . . . . . . . . . . . . . 34

5.2 Percent difference in $C_{L}$ 's between experimenatal and computed results for conventional and morphed wings at $0^{\circ}$ angle of attack . . . . . . . 41

5.3 Percent difference in $C_{L}$ 's between experimental and computed results for conventional and morphed wing at $7^{\circ}$ angle of attack . . . . . . 45 


\section{List of Figures}

2.1 Induced drag acting on an airfoil . . . . . . . . . . . . . . . . . . 3

2.2 Adverse yaw acting on wing [19] . . . . . . . . . . . . . 4

2.3 Bell shaped lift distribution curve compared with elliptical and other powers of sine $[3] \ldots \ldots \ldots \ldots \ldots \ldots$

2.4 Schematic of the Horten-IV[4] . . . . . . . . . . . . . 6

2.5 Horten-IV at Mississippi State University[4] . . . . . . . . . . . . 6

2.6 The PUL-10 [4] . . . . . . . . . . . . . . . . . . . . . . . 7

2.7 Northrop Grumman Smart Wing program [7] . . . . . . . . . . . . . 9

2.8 Scaled models of the morphed and conventional wing . . . . . . . . . 11

3.1 Cross-section detailing individual airfoils of the morph wing . . . . . 13

3.2 Top view of the wing . . . . . . . . . . . . . . . . . 14

3.3 Side view with built in dihedral . . . . . . . . . . . . . . . . 14

3.4 Geometry showing the elevons . . . . . . . . . . . . . . . . 16

3.5 Tip positions with and without washout . . . . . . . . . . . 16

3.6 Control positions . . . . . . . . . . . . . . . . . . 17

3.7 A view of the mesh created by CMARC . . . . . . . . . . . 18

3.8 Tip deflections of morphed wing . . . . . . . . . . . . . 18

4.1 Typical contour plot generated by Postmarc . . . . . . . . . . . . . . 24

4.2 NACA0010 used for benchmarking . . . . . . . . . . . . . 25

4.3 Comparison of experimental and CMARC results for a NACA0010 wing $[14] \ldots \ldots \ldots \ldots \ldots \ldots$

5.1 Sectional $C_{l}$ at $0^{\circ}$ angle of attack of conventional and morphed wings 28

5.2 Sectional lift at various control positions and $0^{\circ}$ angle of attack for conventional(top) and morphed wing (bottom) . . . . . . . . . . 29

5.3 Comparison of conventional and morphed wing $C_{L}$ 's at $0^{\circ}$ angle of attack 30

5.4 Sectional induced drag at various control positions and $0^{\circ}$ angle of attack for conventional(top)and morphed wing (bottom) . . . . . . 31

5.5 Comparison of conventional wing and morphed wing $C_{D_{i}}$ 's at $0^{\circ}$ angle

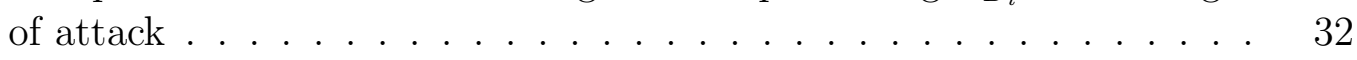


5.6 Comparison of $C_{L}{ }^{\text {'s }}$ and $C_{d_{i}}$ 's at $0^{\circ}$ (top) and $7^{\circ}$ (bottom) angle of attack 33

5.7 Comparison of moment coefficients at $0^{\circ}$ (top) and $7^{\circ}$ (bottom) angle of

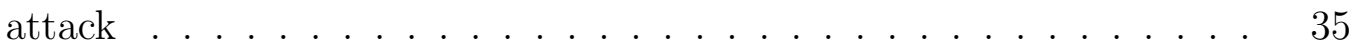

5.8 Comparison of yawing coefficients at $0^{\circ}$ (top) and $7^{\circ}$ (bottom) angle of attack . . . . . . . . . . . . . . . 36

5.9 Comparison of rolling coefficients at $0^{\circ}$ (top) and $7^{\circ}$ (bottom) angle of attack . . . . . . . . . . . . . . 37

5.10 Control positions 1 (left) and 2 (right) of conventional wing . . . . . 38

5.11 Control positions 3 (left) and 4 (right) of conventional wing . . . . . . 38

5.12 Control position 5 of conventional wing . . . . . . . . . . . . 39

$5.13 \mathrm{Cp}$ at control positions 1 (left) and 2 (right) of conventional wing . . 39

$5.14 \mathrm{Cp}$ at control positions 3 (left) and 4 (right) of conventional wing . . 40

5.15 Control positions 1 (left) and 2 (right) of morphed wing . . . . . . . . 40

5.16 Control positions 3 (left) and 4 (right) of morphed wing . . . . . . . . 40

5.17 Control position 5 of morphed wing . . . . . . . . . . . . . 41

5.18 Comparison of experimental and CMARC results for conventional (top) and morphed wings (bottom) at $0^{\circ}$ angle of attack . . . . . . . . . . . 42

5.19 Comparison of experimental and CMARC results for conventional (top) and morphed wings (bottom) at $3.5^{\circ}$ angle of attack . . . . . . . . 43

5.20 Comparison of experimental and CMARC results for conventional (top) and morphed wings (bottom) at $7^{\circ}$ angle of attack . . . . . . . . . .

5.21 Comparison of experimental and CMARC moment coefficients at $0^{\circ}$ angle of attack for conventional (top) and morphed (bottom) wing . .

5.22 Comparison of experimental and CMARC moment coefficients at $7^{\circ}$ angle of attack for conventional (top) and morphed (bottom) wings .

5.23 Comparison of experimental and CMARC results for yaw (top) and roll (bottom) coefficients at $7^{\circ}$ angle of attack . . . . . . . . . .

9

9

0

0




\section{Chapter 1}

\section{Introduction}

\subsection{Background}

The wing morphing project at WVU called "Control of a swept wing tailless aircraft through wing morphing" was started in 2003 largely due to the efforts of Mr. Richard Guiler and my advisor Dr. Wade Huebsch. The idea was inspired from the pioneering work of Dr. Reimar Horten and Dr. Karl Nickel who theorized the usage of a bell shaped lift distribution to reduce the adverse yaw at wing tips. The last of the flying Horten's developed on 1940's Germany, the Horten-IV was extensively studied at the aerophysics department of Mississippi state university. Based on their studies and Reimar Horten's last design the PUL-10 the work at WVU was started.

\subsection{Past research}

Though tailless swept wing aircraft hold great promise in improving aerodynamic performance, they have been detrimentally effected by the problem of adverse yaw. This adverse yaw could be explained as a result of drag. While initiating a roll movement by deflecting the elevon, the increase in lift on the wing also results in an increase of the induced drag. This difference in drag between the wings results in a yaw moment in a direction opposite to that of the roll direction, termed adverse yaw. In conventional tailed airplanes this problem of adverse yaw is overcome by the 
movement of a rudder.

For tailless swept wing aircraft, this problem has been countered by introducing a washout (wing twist with the leading edge of the wing tip having a negative angle when compared to the root airfoil). After a study of various gliders, Dr. Reimar Horten developed the use of a bell-shaped lift distribution curve. It had been observed by Lippisch, the introduction of washout towards wing tips reduced effects of adverse yaw. This bell-shaped lift distribution curve was then developed using a washout at the wing tips. Based on the studies conducted by the team at the Mississippi State University, it was concluded that the handling characteristics of the Horten -IV could be improved if there was a way in which the washout of the wing could be controlled. But due to the lack of technological advances the PUL-10 developed by Siegfried Panek and Dr. Reimar Horten in the early 1980's, had to be built with a fixed $10^{\circ}$ of total washout. At WVU, assuming the PUL-10 represented the state-of-the-art the wing morph of a scaled wind tunnel model has been built so as to control the twist of the wing tip and thus the washout. The initial wind tunnel testing of the morphed wing compared to a wing with built in washout indicated that the lift over drag ratios in the cruise configuration could be $40 \%$ better than the elevon-equipped wing in certain conditions.

\subsection{Current work}

The current work helps to address the next stage in the project to test the morphed wing at various flight conditions. In support of this testing, a three dimensional model of the wing was developed and tested with an aerodynamic panel code called CMARC ${ }^{\circledR}$ [13]. CMARC was used to calculate the coefficient of lift, $C_{L}$, and the coefficient of drag, $C_{D}$, terms. Similar tests have also been conducted on a conventional wing with CMARC. Preliminary work to improve upon the panel code by selecting appropriate viscous models that can be used for further testing was also initiated. Based on the computational results an attempt to explain the flow physics in the wing tip region has been made. 


\section{Chapter 2}

\section{Literature review}

Tailless aircraft have been around for a long time, staring with Dr. Alexander Lippisch a German pioneer of aerodynamics and his tailless airplanes during 19201940 producing the two famous Storch and Delta series, monoplanes with sweepback. The idea of 'all wing' aircrafts was also addressed by John Northrop [1]. Pioneers in the field included the Horten brothers, Reimar and Walter, and their series of Horten tailless aircrafts.

One of the main advantages offered by these swept-back tailless aircraft was the significant reduction of drag. These planes did not have a fuselage and vertical tail sections, there by reducing the parasitic drag. The entire body produces lift unlike a normal aircraft where the fuselage produces little or no lift. Drag can be broken up into two main components: induced drag and parasitic drag. The induced drag simply speaking is, drag due to lift.

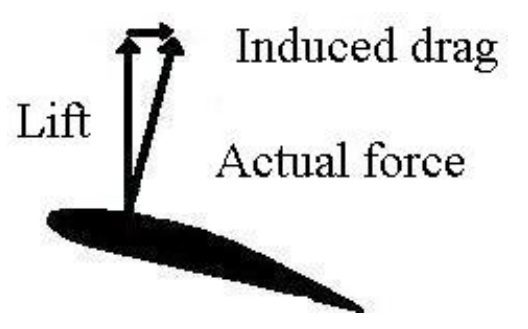

Figure 2.1: Induced drag acting on an airfoil

Induced drag can be explained by circulation theory: flow circulation around the 
wings cause pressure waves which tend to reduce the curvature of the streamlines around the leading edge. This means the wind striking the wing comes from above and not from the front. This results in the shift between the theoretical lift vector and the actual force as shown in Figure 2.1. The angular deflection is small and has little effect on the lift; however, there is an increase in the drag equal to the product of the lift force and the angle through which it is deflected. Since the deflection is itself a function of the lift the additional drag is proportional to the square of the lift. At wing tips this induced drag can be responsible for the stall.

Parasitic drag is the component which arises due to the friction between the fluid and the surface of the body. Simply put it is the frictional resistance offered to the bodies motion in the opposite direction. Since these airplanes did not possess a fuselage and a vertical tail section a large amount of parasitic drag was reduced.

The primary factor which affected the stability of the tailless aircraft was the problem of adverse yaw. Adverse yaw can be explained due to induced drag being produced. When the airplane is making a roll maneuver, done by deflecting the elevons on each of the wings in the opposite direction, there is a difference in lift being produced on each of the wings as well as an induced drag differential.

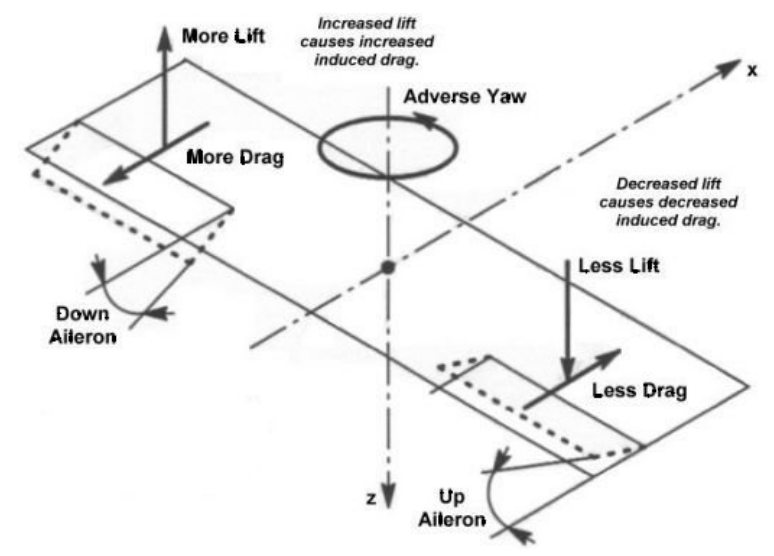

Figure 2.2: Adverse yaw acting on wing [19]

This differential results in dragging the up-moving wing in the opposite direction of the desired roll. As depicted in Figure 2.2, the wing is executing a roll motion to the right and the adverse yaw pulls the wing toward the left. 
In conventional aircraft this problem can be countered by deflecting the ailerons at different angles and by deflecting the rudder. The lack of a rudder in a tailless aircraft makes it very difficult to counter the problem with just differential elevons. Based on the work done by Lippisch a washout was implemented at the wing tips. It was observed that including a washout not only delayed stall at the wing tips, but also reduced the effects of adverse yaw.

Despite all the advancements, most tailless aircraft suffered from stability and control issues. The lack of a vertical tail meant the yaw motion had to be controlled by effective use of the elevons. In most modern tailless aircraft this is done by using the ailerons. The Horten-IV had three sets of elevons on each wing, various combinations of which reduced adverse yaw effects.

During and after the war years Dr. Reimar Horten had theorized the bell shaped lift distribution curve as a cure for adverse yaw. This bell shaped lift distribution, would minimize adverse yaw since the tips were loaded downward so the result is a small amount of induced thrust at the wing tips. This curve Figure 2.3 was obtained using washout of the wing. Based on these studies the Horten-IV, a swept-back tailless aircraft (see Figure 2.4) was developed towards the end of the war. Work on the flying wings took a back stage largely due to the war and destruction.

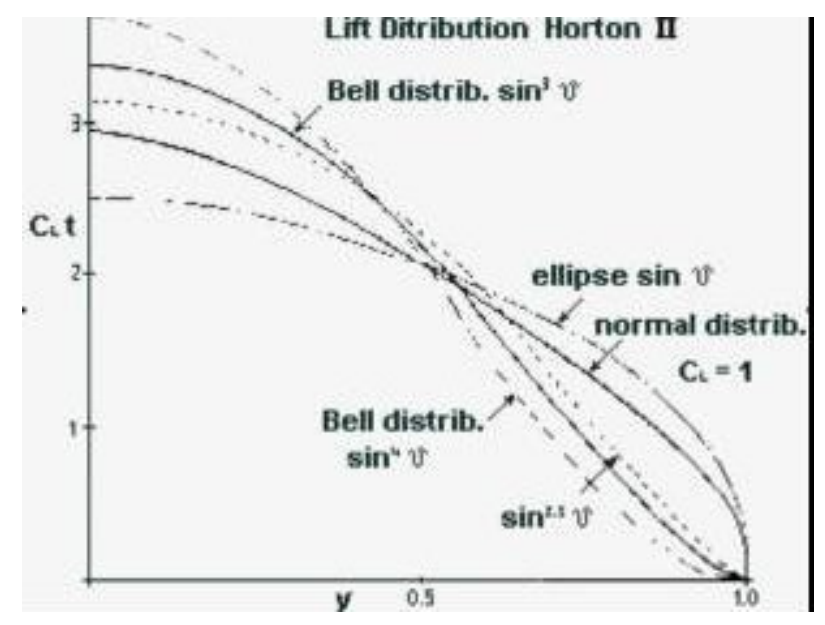

Figure 2.3: Bell shaped lift distribution curve compared with elliptical and other powers of sine [3]

The Horten-IV had by 1959 been passed on to Mississippi State University for 


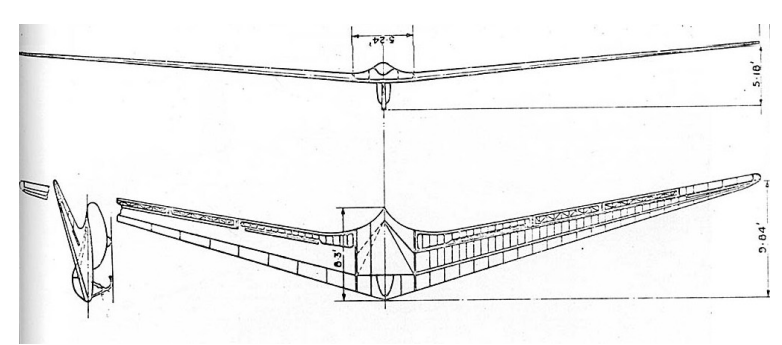

Figure 2.4: Schematic of the Horten-IV[4]

evaluation (see Figure 2.5), which was done by Dezso Gyorgy-Falvy at the aerophysics department. This work was aimed at determining the reasons for lower than estimated performance. The best gliding ratio for the Horten-IV was expected to be 0.37 , however the flight test results were all much lower. It was also observed that there was a very low maximum lift coefficient and the minimum drag coefficient was barely lower than that of a conventional design, which increased rapidly with the lift coefficient. Clearly there were many influential factors that that resulted in this disappointing behavior

Based on the studies it was concluded that the high induced drag coefficients were due to excessive negative elevon deflections which were needed to produce high $C_{L}$, low Reynolds number at the tip and excessive taper [2]. Some of the possible ways to improve the performance as suggested by Dezso, included the usage of a low drag laminar airfoil to delay tip stall and elimination of large control deflections by means of variable sweep or twist.

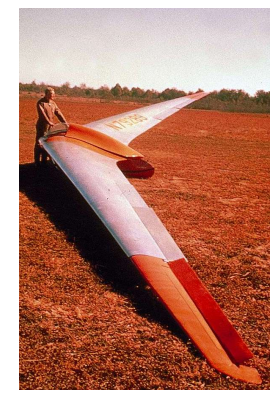

Figure 2.5: Horten-IV at Mississippi State University[4]

The Hortens and Dr. Karl Nickel came to the same conclusion [3]. The Hort- 
ens and Nickel also modeled elevon control inputs as effective washout. Along with Siegfried Panek, Dr. Horten designed the PUL-10 (see Figure 2.6) in the late 1980's. The PUL-10 had a lot of design changes compared to the original Horten-IV [4] the details of the PUL-10 have been provided in table 2.1. Most importantly the tip airfoil had been changed to a symetrical airfoil thus delaying tip stall.

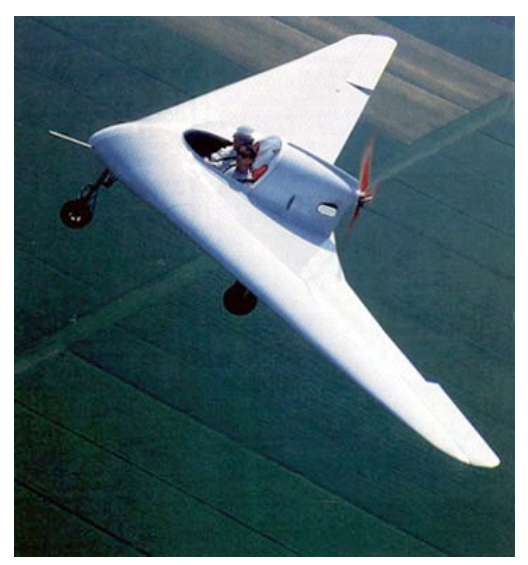

Figure 2.6: The PUL-10 [4]

Table 2.1: Details of PUL-10 [4]

\begin{tabular}{|r|r|}
\hline Aspect ratio & 6.485 \\
\hline Wing sweep & $35^{\circ}$ \\
\hline Wing Dihedral & $2^{\circ}$ \\
\hline Wing twist (nonlinear twist) & $10^{\circ}$ \\
\hline
\end{tabular}

The PUL-10 represented the state of the art tailless aircraft in the 1980's and had very good handling characteristics, but may have still suffered some adverse yaw effects and took an experienced pilot to fly it.

\subsection{Wing Morphing}

The history of aviation started with man wanting to fly like birds. In spite of all the technological innovations, after roughly 100 years of aviation we are still far from being as efficient and maneuverable as birds in flight. The primary difference 
lies in the dynamic ability of a bird to be able to change its wing shape as required; thickness, planform, twist etc. Some limitations of conventional aircraft include: task specificity, they have undesirable aeroelastic properties, and their control surfaces can cause premature flow separation. Any improvement which can modify the existing geometry of the wing in order to achieve any one of the above flight characteristics of birds can be termed as wing morphing.

The ideas of wing morphing are as old as that of aviation. The Wright flyer had wing warping; the tips of their wing could be twisted relative to the rest of the wing [5]. The Wright brothers used this wing warp mechanism for roll control in their 1901, 1902 gliders and on the 1903 successful flyer. Modern aircraft however use ailerons for roll mechanism. Today considerable interest has been expressed in morphing technologies as they offer the military an aircraft capable of multi-tasking and multi- missioning. Morphing of wings is achieved broadly in three different ways.

\subsubsection{Smart Materials}

It has been outlined by NASA Langley that 'smart' technologies are one of the key areas of thrust in their "Aircraft Morphing program"[6]. Smart materials have the ability to change shape or size simply by adding a little bit of heat, or to change from a liquid to a solid almost instantly when near a magnet. Smart materials, smart structures, acoustics, controls and their integration have been recognized as the key disciplines. All the above technologies being implemented in various stages of flight to decrease the exterior noise, increase efficiency and tackle weather.

NASA Langley Research Center has been conducting research with smart technologies in a wide variety of ways. The goal in most of the projects has been to do away with conventional moving control surfaces and to achieve control by the use of these smart materials. One advantage of smart materials are its multi-functionality, performing differently under different conditions. Most of the research involves using smart materials to change the shape of the wing, as performed by the control surfaces. The Northrop Grumman smart wing program along with NASA Langley is a prime example of this [7]. The smart wing program uses Nickel-Ttitanium (NiTi) 
shape memory alloys to achieve hingeless-smooth contoured, trailing edge flap control surface and variable spanwise wing twist (see Figure 2.7). This makes it possible to achieve extremely smooth deflections of the control surfaces, thereby reducing the parasitic drag and also preventing the onset of separation.

\section{Conventional Control Surface}

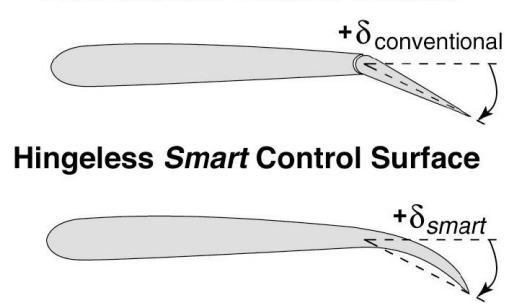

Figure 2.7: Northrop Grumman Smart Wing program [7]

\subsubsection{Flight Control using fluidic effectors}

Instead of a moving control surface the morphing may also be achieved by a combination of propulsive forces, micro surface effectors and fluidic devices placed to provide control to the aircraft. Virtual shaping using synthetic jet actuators is one such example of a morphing technology being used to alter the aerodynamic shape of the airfoil using unsteady suction and blowing to enhance the lift and/or reduce drag.

Virtual shaping using a synthetic jet works by changing the apparent shape of the airfoil. Experimental work done by Chatlynne et al[8] showed that it is possible to modify the apparent aerodynamic shape of an airfoil at low angles of attack in this fashion. Some of the promising features of synthetic jet actuation at leading edges appeared to shift the stagnation line inducing an effect similar to a low angle of attack, thereby increasing the lift [9] .

\subsubsection{Structurally induced morph}

The third and by far the most promising morphing technology for near-term application is to induce morph in a wing by structural modifications. This is currently 
the most well documented and feasible option available. The morphing technologies listed above are all in their experimental stages with road blocks to overcome, and many of them have not been tested in actual flights. Structurally induced morph can include wing curling, wing twisting, variable wing sweep and variable planform.

Some examples with variable twist will be mentioned below as the present work concerns the use of variable twist. A team at the University of Florida has been very successful in implementing various morphing strategies like variable twist, wing curl, leading edge twist and variable gull-wing angling in their micro air vehicle. Wing twist essentially is the twist of the wing under loading in-flight to produce a passive washout that helps smooth the flight path. Such a concept can be extended to achieve roll moments. In two different cases morphing was applied either by the simple pulling of a thread or by a torque rod mechanism. The morphing results from the actuation of the torque rods. In both the cases, there were significant roll and yaw moments acting on the airplane. In general it was concluded that the roll rate generated by morphing was capable of commanding roll maneuvers [10].

In all the morphing cases mentioned above, the variable twist offers possible benefits for tailless airplanes. These technological advancements help us make the tailless airplane achieve their true efficiency. The variable washout allows one to overcome the adverse yaw and offers better roll control of the airplane.

\section{$2.2 \quad$ Wing morphing at WVU}

At West Virginia University the morphed models were developed and constructed by my colleague Richard Guiler[11]. The model needed to be strong enough to avoid flutter-oscillation caused by aerodynamic forces, as well as flexible enough to perform the required twist. All this had to be done on a model with minimum weight. After a couple of initial models the present generations of models to be described were developed.

To achieve a smooth twist at the wing tip, a small section (the outer $33 \%$ span) preceding the wing tip was selected and broken down into 10 equally spaced free flowing sections. These 10 sections were connected at the trailing edge with the help 
of a spring loaded $2 \mathrm{~mm}$ teflon cable. This complete section was then covered by a $0.25 \mathrm{~mm}$ thick latex skin which allows forming a smooth curve fit. The actuation of the model is done with the help of a torque rod which runs through the span close to the trailing edge. It has a $90^{\circ}$ bend and a $50 \mathrm{~mm}$ section extending toward the trailing edge.
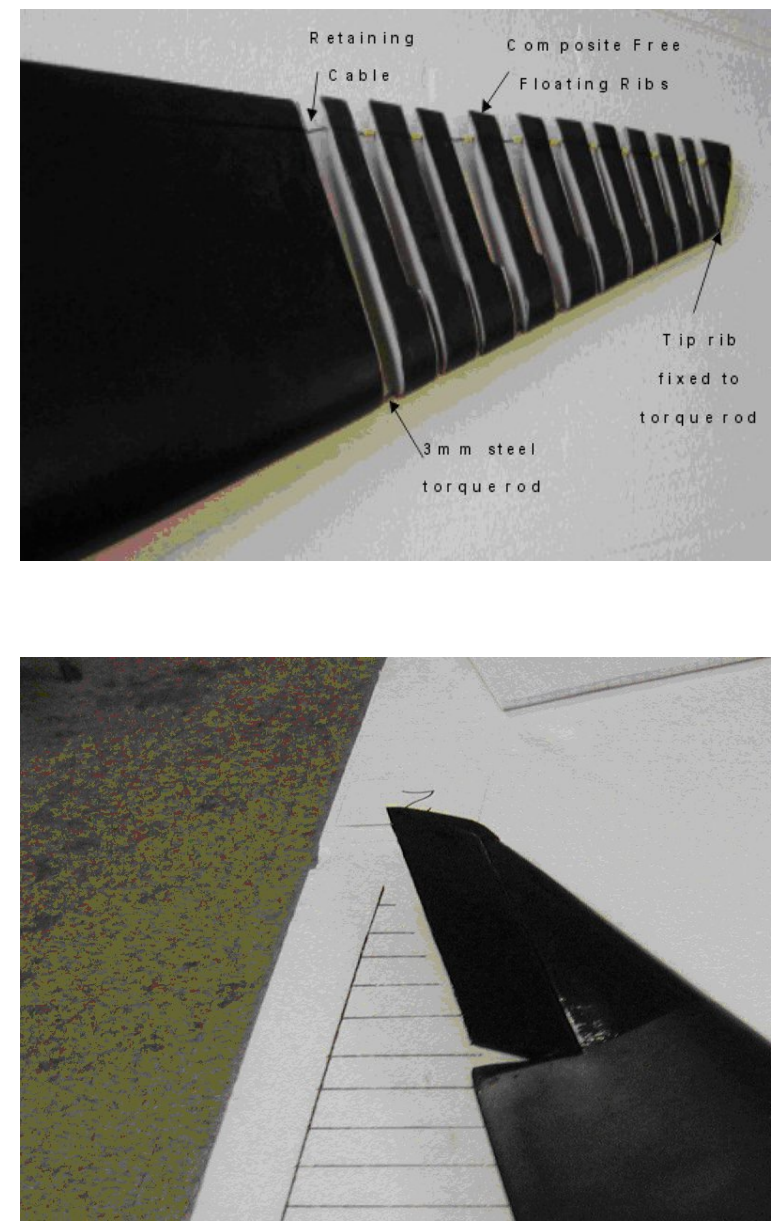

Figure 2.8: Scaled models of the morphed and conventional wing 


\section{Chapter 3}

\section{Geometry}

Two wing geometries were modeled, one the PUL-10 which would serve as the conventional wing and the other the morphed wing. Both of these wing geometries were created to match the scaled models that were to be tested in the wind tunnel at WVU. The idea is to numerically calculate the flow fields for the wings and to compare them to the experimental studies.

The geometry of the airplane at WVU consists of two different airfoils along the half span. At the root and approximately at 33\% span from root are two MH-78 sections, designed by Martin Hepperle [12], to have better performance than the original Horten airfoil at low Reynolds numbers. These airfoils were designed for man carrying gliders, with moderate sweep. The airfoils have of $19 \%$ thickness at the root and $14.4 \%$ at $33 \%$ span. The wing tip airfoil has been changed from that of the original Horten symmetric 10\% to a NACA0010. The shape and characteristics of these airfoils are almost identical. Also the NACA0010 has been extensively studied and documented. Figure 3.1 shows the three airfoil sections, the first and the largest being the MH-78 19\% thickness, the root section, the next the MH-78 14.4\% thickness and the last, the wing tip the NACA0010 section.

The geometries of the PUL-10 and henceforth the conventional wing and the morphed wing differed from each other largely in the outer $1 / 3^{r d}$ region of the wing. This difference is due to their respective control mechanisms and the degree of washout at the wing tip. The conventional wing configuration has a washout of 10 degrees built 


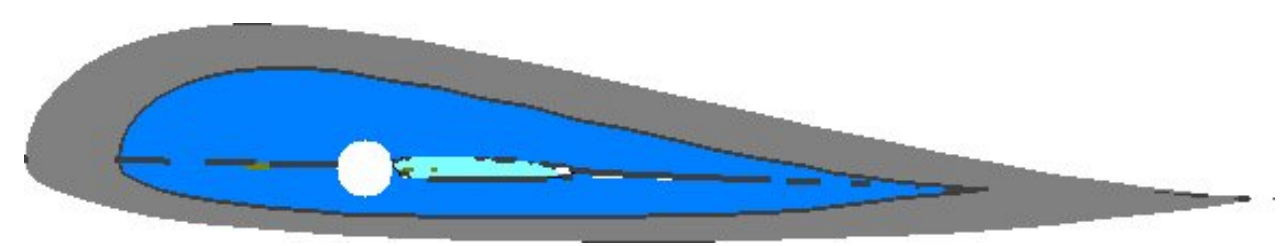

Figure 3.1: Cross-section detailing individual airfoils of the morph wing

in at the wingtip. Washout refers to the lower geometric incidence of the outboard section compared to the root section. Thus the outboard section has a lower angle of attack relative to the root section thereby delaying stall at the wing tips. This built in washout at the wing tips along with the effective usage of elevons helps achieve roll moment in the conventional wing of a tailless aircraft.

The morphed wing has no built in washout. At its neutral position all the three wing sections are at the same angle of incidence to each other. Effective roll moment for the morphed wing is achieved by the use of variable wing twist through the morphing mechanism.

These geometries were created on Loftsman, a commercial 3-D drawing software package which sets up geometries for the panel code CMARC, in its format, more of which will be covered in the next chapter. Loftsman helps to create a * in file as the input file for CMARC. A typical CMARC input file contains panel parameters like panel coordinates, input conditions, wake definitions, etc. Loftsman helps append each one of these geometrical definitions into a complete input file. Input files for CMARC can be set up without the use of Loftsman, but this procedure is very time consuming and the designer needs to have good imagination of how the final geometry turns out, since there is no way to view the geometry on CMARC. Figures 3.2 and 3.3 detail the top view and the side view of the conventional wing as created on Loftsman.

The geometries created were to be tested at various angles of attack and at various control positions (various positions of the elevons or wing twist). 


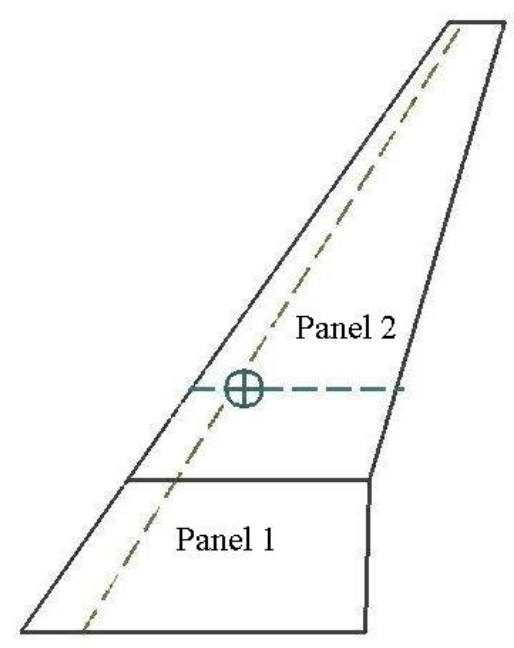

Figure 3.2: Top view of the wing

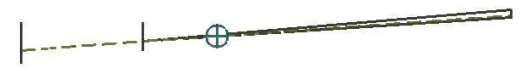

Figure 3.3: Side view with built in dihedral

\subsection{Geometry details}

The geometry creation started with the coordinates for the airfoil sections. Each airfoil section had to be input into Loftsman in a ${ }^{*}$.sd (section data) format. Each *.sd format file contains the thickness-to-chord ratio followed by the coordinates. An example *.sd file has been provided in appendix A. Once the ${ }^{*}$.sd files were created, they needed to be merged as part of a wing file. The ${ }^{*}$.wi wing file contains the section details, number of spars per section, the chord length and most importantly for the current work, incidence of that section with respect to the root chord. This incidence angle was used to specify the varying twist required for the various morphed positions. With all these details, various wing files for each one of the desired configurations were created. An example of a wing file has been provided in appendix A. The geometry is broken up into two panels (see table 3.1). The first panel is the section enclosed between the two MH-78 wings. The next patch is the section enclosed between the MH-78 and the NACA 0010 airfoil sections. Figure 3.2 shows the two panels, labeled 
panel 1, panel 2 .

Table 3.1: Geometrical details of the wing

\begin{tabular}{|r|r|r|}
\hline Panel number & 1 & 2 \\
\hline Area $\left(\mathrm{mm}^{2}\right)$ & 48428 & 73944 \\
\hline M.A.C $(\mathrm{mm})$ & 308.64 & 175.25 \\
\hline Sweep & $35^{\circ}$ & $35.02^{\circ}$ \\
\hline Dihedral & $3.97^{\circ}$ & $3.95^{\circ}$ \\
\hline Average area & \multicolumn{2}{|c|}{122372} \\
\hline Average M.A.C & \multicolumn{2}{|c|}{222.59} \\
\hline Span & \multicolumn{2}{|c|}{636} \\
\hline Aspect ratio & \multicolumn{2}{|c|}{6.61} \\
\hline
\end{tabular}

As was mentioned before, the main difference in the geometries were the washouts (see Figure 3.5). For the conventional wing, provisions had to be made to include the panels that would deflect as part of the elevon. For this purpose the outer region of the actual model was measured using a standard measuring tape and then traced on the designed model. Using this trace, all the panels that would constitute the elevon were recognized (See highlights in Figure 3.4). All of these panels were then grouped as part of a 'tilt panel' group. CMARC would recognize these panels and deflect their normal vectors without modifying their physical geometry. Care had to be taken to identify the correct panels, especially toward the corner points. Since the actual panels do not exist on the physical model, some panels were partly inside the 'tilt group' and some partly outside. Based on the actual position, some of these panels were either ignored or attached to the existing group. Thus there was some approximation made, but since the meshes constructed were relatively fine close to the wing tips, it is believed that these panels individually would not constitute much toward the overall magnitude of the coefficients.

The twist in the actual morphed wing is achieved by the use of a torque rod mechanism. To make the profile of the wing twist as smooth as possible for the experimental model it was decided that a quadratic fit was needed this was done by breaking the outer $1 / 3^{\text {rd }}$ region of the wing into 10 equally spaced ribs. For the computational wing model, the twist was achieved in the same basic way; the mesh 


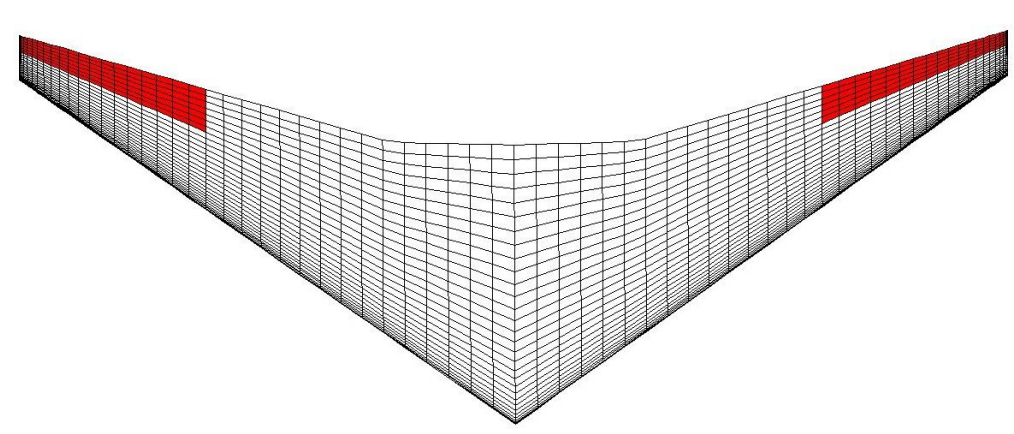

Figure 3.4: Geometry showing the elevons

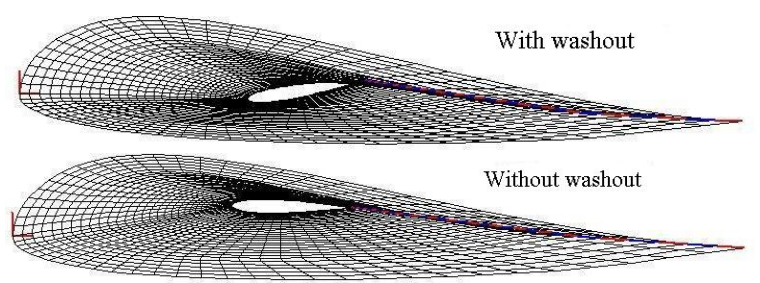

Figure 3.5: Tip positions with and without washout

was biased (see Figure 3.7)to be smaller around the wing tip, which allowed a twist with a fit close to a quadratic profile as shown in Figure 3.8.

The various positions of the morphed wing were obtained relatively easily by twisting the wing tip by the desired angle. There were five positions of orientations : $+3.5^{\circ}$, $+7^{\circ}, 0^{\circ},-3.5^{\circ}$ and $-7^{\circ}$. These orientations also correspond to the conventional wing deflections of the elevon. Table 3.2 details the control postions with their respective angle of twists. Figure 3.6 shows the five control positons in decending order of angle of twist.

Table 3.2: Control postions and their angle of twists

\begin{tabular}{|c|c|}
\hline Control positions & Angle of twist \\
\hline 1 & $-7^{\circ}$ \\
2 & $-3.5^{\circ}$ \\
3 & $0^{\circ}$ \\
4 & $+3.5^{\circ}$ \\
5 & $+7^{\circ}$ \\
\hline
\end{tabular}




\subsection{Mesh details}

Unlike CFD mesh generation, panel codes do not require dense meshes. The meshes for panel codes are relatively coarse and do not require the precision of a CFD mesh. The mesh created discretizes the geometry into quadratic panels. Care must be taken to avoid creating meshes that do not capture the exact geometry and cause negative volumes. As such, there was a certain degree of approximation involved at the intersection of the two MH-78 airfoils close to the trailing edge.

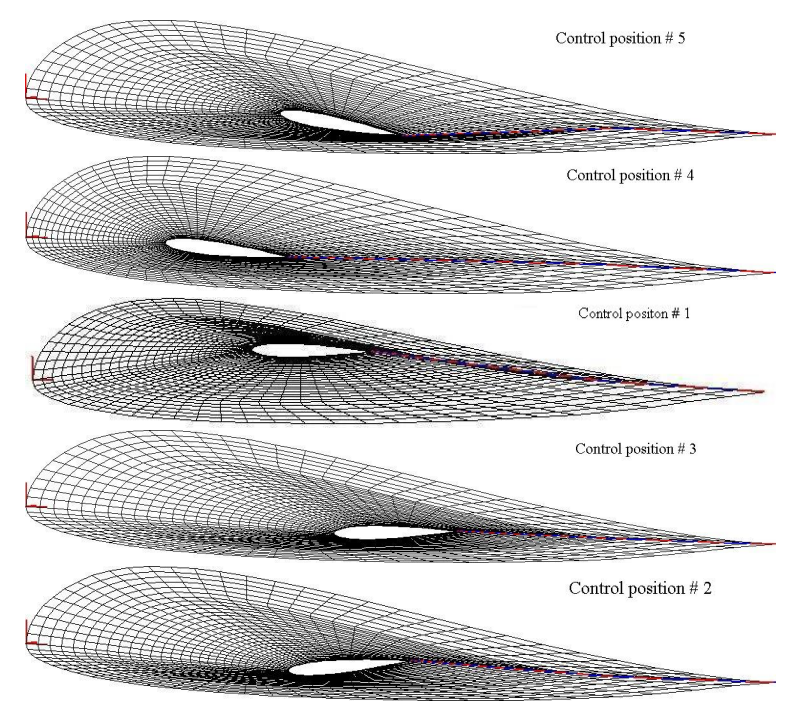

Figure 3.6: Control positions 


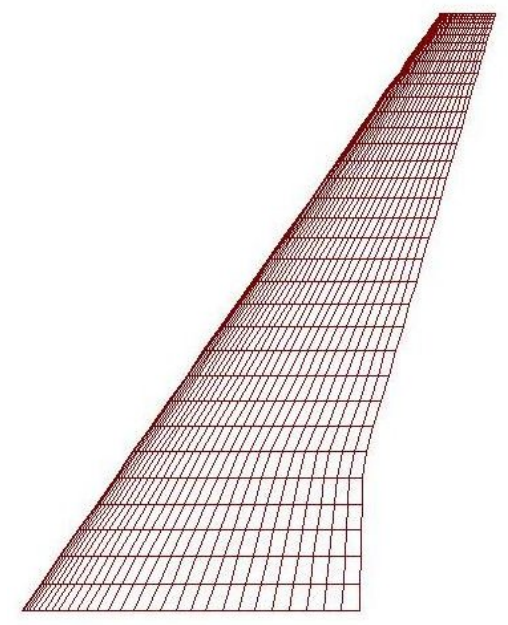

Figure 3.7: A view of the mesh created by CMARC

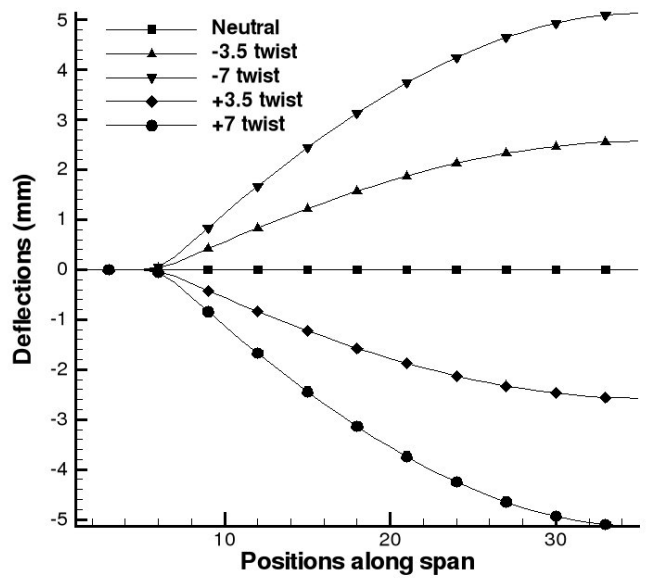

Figure 3.8: Tip deflections of morphed wing

The meshes were biased towards the wing tip and the leading edges. The biasing at the wing tip was necessary since the primary focus was investigating the induced drag. The biasing also helped in achieving a quadratic twist in the wing Figure 3.8 depicts the quadratic nature of the twist being induced in the morphed wing. The deflection has been plotted against the columns of panels. Along the span the wing had 35 columns and along the chord there were 30 rows. 


\subsection{Input conditions}

The wind tunnel experiments on the morphed wing and the conventional wing were conducted at 10, 15 and $20 \mathrm{~m} / \mathrm{sec}$. A few tests were also conducted at higher velocities close to $25 \mathrm{~m} / \mathrm{sec}$. At higher speeds it was observed that the latex covering on the morphed wing started to bubble and there was a gradual onset of flutter at the wing tip. Thus it was decided that $20 \mathrm{~m} / \mathrm{sec}$ would be the maximum cruise speed for the model in the wind tunnel. Therefore all the computational runs were conducted at $20 \mathrm{~m} / \mathrm{sec}$. The speed of sound was taken as $332 \mathrm{~m} / \mathrm{sec}$. Since the analyses were all inviscid there was no requirement for the density and viscosity. 


\section{Chapter 4}

\section{Panel codes and CMARC}

It was decided to perform the numerical analysis with a panel code. Panel methods can be broadly defined as methods where the surface geometry of the body can be broken up into a set of panels, which represent elementary potential flows such as source, vortex, and doublet flows, to compute the resulting flow field. For the preliminary numerical investigation panel codes were chosen over three dimensional CFD codes since they converge much faster, they do not require high end computing resources, they can handle a wide range of geometries and they offer good prediction capabilities for certain types of aerodynamic flows. Future analysis will be performed with other CFD codes which have the capability to solve for viscous and turbulent characteristics.

An ideal incompressible fluid with zero vorticity at any instant will not generate vorticity. This is termed an irrotational flow and can be represented as

$$
\nabla \times \vec{U}=0
$$

For an irrotational flow, the velocity can be expressed as the gradient of a scalar potential

$$
\vec{U}=-\nabla \phi
$$

where $\phi$ is called the velocity potential. If you apply this equation to the definition of incompressibility, $\nabla \cdot \vec{U}=0$, the r result is the governing equation for potential flows: 


$$
\nabla^{2} \phi=0
$$

which is Laplace's equation.

Potential flow theory is devoted to the solution of the Laplace's equation. A common view of the solution is the concept of a 'singularity'. These are algebraic functions which satisfy Laplace's equation and can be combined to construct flows. The most familiar of these singularities are the source/sink, vortex and doublet singularities. Distribution of sources and doublets can be shown by the use of Green's Theorem. According to this theorem if $\phi_{1}$ and $\phi_{2}$ are two scalar functions of positon , we have

$$
\oiint_{S_{o}}\left(\phi_{1} \operatorname{grad} \phi_{2}-\phi_{2} \operatorname{grad} \phi_{1}\right) \cdot \vec{n} d S=\iiint_{R_{o}}\left(\phi_{1} \nabla^{2} \phi_{2}-\phi_{2} \nabla^{2} \phi_{1}\right) d \tau
$$

Where $R_{o}$ is a region enclosed by the surface $S_{o}$. Let us set

$$
\phi_{1}=\frac{1}{r}, \phi_{2}=\phi
$$

where $r$ is the distance from a fixed point $P$ to another point and $\phi$ is a harmonic function. Then equation 4.0 becomes

$$
\oiint\left(\frac{1}{r} \operatorname{grad} \phi-\phi \operatorname{grad} \frac{1}{r}\right) \cdot \vec{n} d S=-\iiint_{R o} \phi \nabla_{2}\left(\frac{1}{r}\right) d \tau
$$

Following the above equations form Karamcheti [13], it can be concluded that the flow may be represented by a distribution of sources alone or doublets alone on the surface of the body. In a low order panel method, the singularities are distributed with constant strength over each panel. Higher order methods can be described as those in which the distribution of the singularities varies quadratically. Higher order methods claim to provide better accuracy in modeling the flow, but at the expense of increased code complexity and computation time [14].

For our studies we chose to use a commercially available panel code called CMARC, which is very similar to PMARC [15](Panel Method Ames research Center), the panel code method developed at NASA Ames. Along with CMARC commercial codes for geometry creation (Loftsman [16]) and for post processing (Postmarc [17]). 
CMARC has the same capabilities offered by PMARC, but was developed in the $\mathrm{C}$ programming language. In addition to modeling potential flows over three dimensional geometries, it can also time step over wakes .CMARC is a low order panel code method; the singularities are distributed with constant strength over each panel. The surface is broken up into quadrilateral panels and each panel has a constant source and doublet distribution.

The geometries are modeled as closed surfaces, dividing the flow field into two regions. One being the flow field of interest over the body, the other being a fictitious flow field called the wake which is the downwash distribution. It is then assumed that the velocity potentials in both the regions satisfy Laplace's equation.

\subsection{CMARC input file}

A typical CMARC input file contains all the parameters needed to perform a complete analysis. It can be broken down into three major sections which contain the general run control information the body and wake geometry, and parameters for some special functions. To make the comparisons valid, the input conditions were kept constant for all the analysis. All the analysis were run at a low free stream velocity of $20 \mathrm{~m} / \mathrm{sec}$ to match experimental conditions. For convenience the geometry was subdivided into several pieces and modeled with sets of panels called patches. For the present problem, the geometry was broken down into two patches along the symmetrical roll plane.

There are primarily three levels of geometric hierarchy available in CMARC. For the first level the section coordinate system is used to define patches. The second level is the component coordinate system followed by the third v.i.z. the assembly coordinate system. Each system allows the components below to be rotated, translated and scaled. This also facilitates the solving of unsteady flows where the geometry can move in a certain fixed pattern with respect to the assembly. The wake geometry section of CMARC is defined so that the body under study can shed wakes from known "separation lines" on the surface geometry.

The wakes in CAMRC are time stepped; with each time step a new row of wake 
panels are appended to the wake and convected downstream. It is up to the user to specify the line of separation along the geometry. For the current problem the separation line was set at the trailing edge, so the wake structure being convected downstream can be studied, with particular focus at the wing tips.

Key parameters controlling the code ( e.g, the number of maximum iterations, the termination criterion etc.) are present at the very beginning of the code. Apart from these specific parameters, parameters to obtain the desired format of the output are also present.

The wing geometries needed to be tested at various angles of attack and also at various control positions. Each one of these tests needed a different input file. For the morphed geometry the parameters that changed were the angles of attack and the twist at the wing tip. This was done by twisting the wing tip by the required angle in Loftsman and exporting the file to create a new input file. Once this file was created, changing the angle of attack was a simple task, requiring the changing of a single parameter.

The process was more complicated for the conventional wing with elevon controls. Once the elevon panels were identified, the panels had to be aligned in the code according to their respective row and column numbers. Once this was done the complete set of panels could be revolved around a specified line which acted as a hinge. Once this was done the user was required to specify an appropriate twist angle. Care had to be taken here as the creation of panels about the symmetric plane may not follow the same numbering order for rows and columns on both sides. Once each one of these file were run through the code, taking between 2-4 minutes to execute, the program outputs a *.out file in ASCII format.

\subsection{Output file}

The output file created by CMARC contains all of the aerodynamic details of the current geometry. The file is designed to give the analyst as much information as possible regarding geometry and aerodynamic data in as compact a space as possible. The idea behind this is to let CMARC do the computing only and to have post- 
processing done separately. Computing should be kept at a minimum in the plotting package.

The output file is divided into roughly three blocks depending on the users specifications. The first usually is a geometry block which contains the geometric details for all created panels. This aids in recreating the grid in the post-processor. This block is followed by an aerodynamic and wake block. These blocks are written for each time step. Aerodynamic data and wake data can be written at both the corner points and the centroids of each panel. The aerodynamic block usually contains the coordinates of the panel followed by the $\mathrm{x}, \mathrm{y}, \mathrm{z}$ velocity components, the velocity magnitude, the pressure coefficient and the local Mach number.

\subsection{Postmarc}

Postmarc is the name of the post-processing package designed to process the .out file generated by CMARC. Initially the author had tried unsuccessfully to create a post processing package on Matlab. It was later decided to switch to Postmarc. The Postmarc interface is like any other computer aided design-CAD package interface; it allows the user to rotate, pan and zoom into the geometry effortlessly. Once the geometry is read, contour plots of pressure, velocity and Mach numbers can be created. It also has the capability of creating animations to view wake shedding. Most importantly pressure cross sections can be viewed by dragging the cursor across the desired section. The following Figure 4.1 depicts a typical pressure contour plot generated on Postmarc.

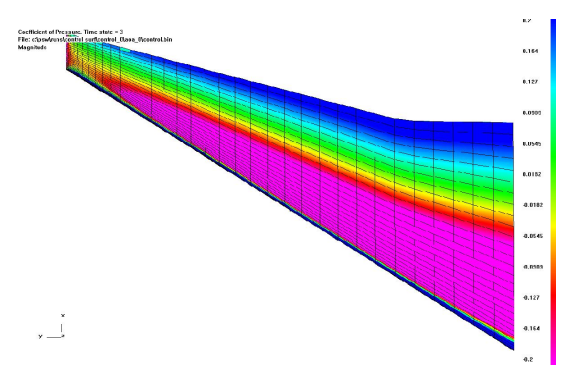

Figure 4.1: Typical contour plot generated by Postmarc 
CMARC was validated using a NACA 0010 wing without any taper or twist. The details of the input file have been provided in the appendix A. Table 4.1 shows the $C_{l}$ 's obtained at various angle of attack which are in good agreement with actual results. Figure 4.3 compares sectional lift coefficients obtained by experiments [18] to those obtained on CMARC. There is a good match of the sectional lift coefficients.

Table 4.1: Performance prediction from CMARC for a NACA 0010 wing

\begin{tabular}{|c|c|c|c|c|c|c|}
\hline sec no & \multicolumn{2}{|c|}{ aoa 3} & \multicolumn{2}{c|}{ aoa 5} & \multicolumn{2}{c|}{ aoa 7} \\
\hline & $C_{l}$ & $C_{d}$ & $C_{l}$ & $C_{d}$ & $C_{l}$ & $C_{d}$ \\
1 & 0.301 & 0.001 & 0.5275 & 0.0042 & 0.7449 & 0.0084 \\
2 & 0.302 & 0.0016 & 0.5258 & 0.005 & 0.7425 & 0.0097 \\
3 & 0.3022 & 0.0017 & 0.5247 & 0.0053 & 0.7408 & 0.0102 \\
4 & 0.3021 & 0.0018 & 0.5237 & 0.0054 & 0.7391 & 0.0106 \\
5 & 0.3016 & 0.0019 & 0.522 & 0.0057 & 0.7363 & 0.0111 \\
6 & 0.3007 & 0.0021 & 0.518 & 0.0062 & 0.7296 & 0.0124 \\
7 & 0.299 & 0.0026 & 0.5089 & 0.0074 & 0.7151 & 0.0146 \\
8 & 0.2934 & 0.0036 & 0.4836 & 0.0095 & 0.6766 & 0.0186 \\
9 & 0.2712 & 0.0056 & 0.406 & 0.0119 & 0.5683 & 0.0235 \\
10 & 0.1917 & 0.0074 & 0.238 & 0.0105 & 0.3402 & 0.0203 \\
\hline
\end{tabular}

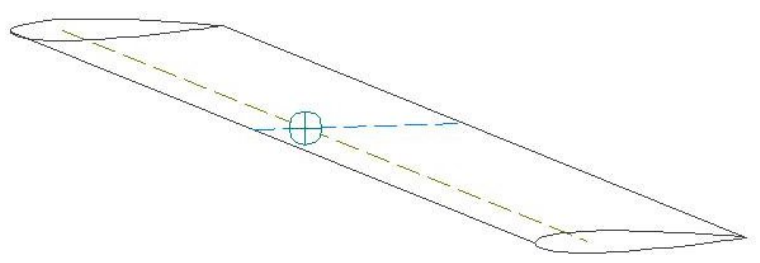

Figure 4.2: NACA0010 used for benchmarking 

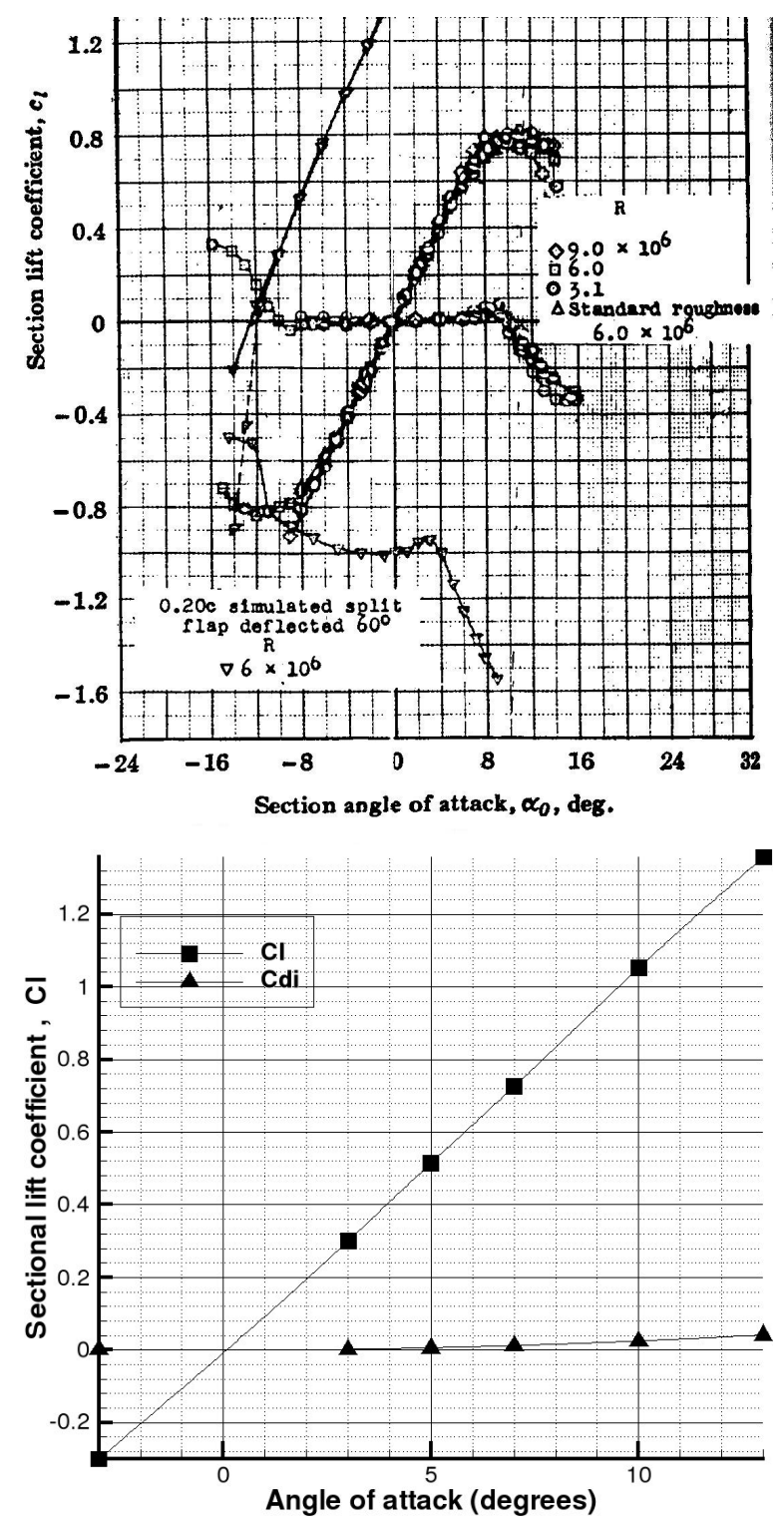

Figure 4.3: Comparison of experimental and CMARC results for a NACA0010 wing [14] 


\section{Chapter 5}

\section{Results and Discussions}

This chapter intends to compare the results obtained using the panel code method CMARC to the experimental results obtained from wind tunnel testing. The wind tunnel testing was carried out by the author's colleague Mr. Richard Guiler.

\subsection{CMARC results}

\subsubsection{Lift and drag characteristics}

Firstly the lift characteristics of the conventional wing and the morphed wing are compared with CMARC. This is done to show that the overall sectional lift characteristics of the morphed wing show improvement over the conventional wing.

Figure 5.1 compares the computed sectional lift coefficients of the conventional and morphed wing at $0^{\circ}$ angle of attack and control position 3 . It can be noticed that the built in washout of the conventional wing results in the dip of sectional lift toward the wing tip. This dip is not observed in the morphed wing due to the lack of washout. Figure 5.2 is a comparison of the sectional lift coefficients of the conventional wing and the morphed wing at various control positions at $0^{\circ}$ angle of attack. The peak as expected occurs at control position 5 which corresponds to a twist of $7^{\circ}$. It can also be observed for all the control positions that the average lift coefficients of the morphed wing are higher than the conventional wing. The overall 


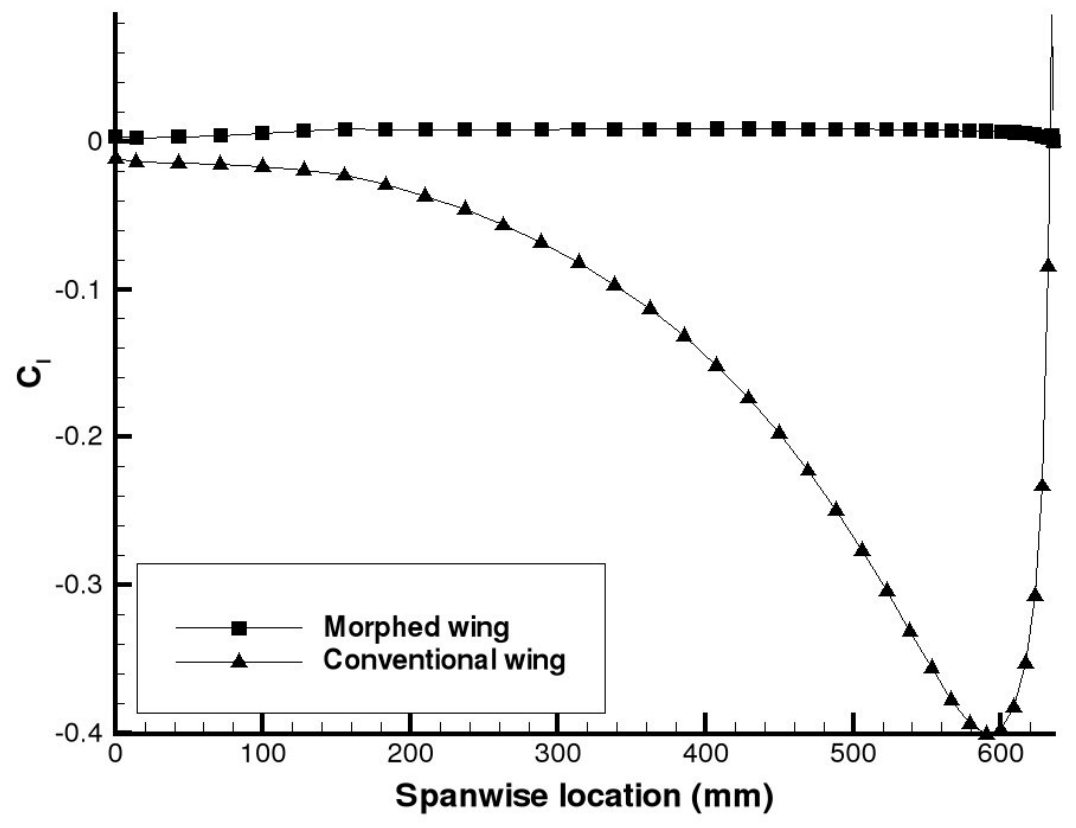

Figure 5.1: Sectional $C_{l}$ at $0^{\circ}$ angle of attack of conventional and morphed wings 

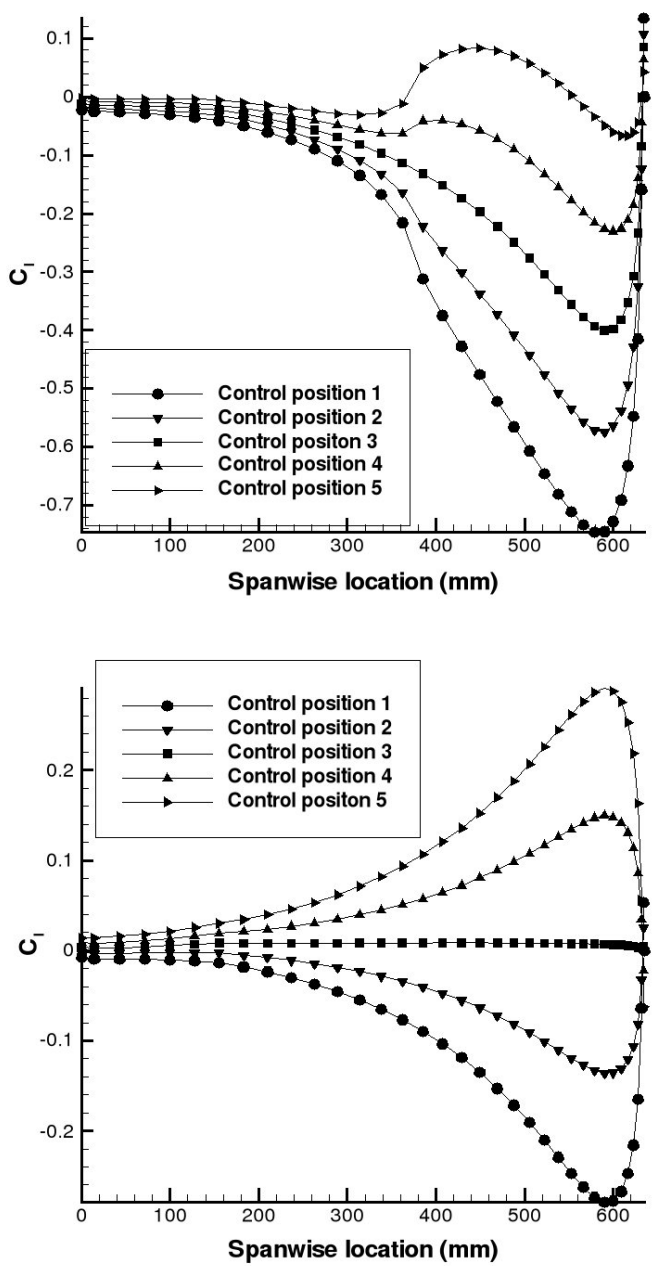

Figure 5.2: Sectional lift at various control positions and $0^{\circ}$ angle of attack for conventional(top) and morphed wing (bottom) 
lift coefficients in CMARC are computed using the Trefftz plane analysis[21] which uses the control volume approach to calculate the lift and the resulting induced drag over the body. Figure 5.3 shows a comparison of the lift at various control positions of the conventional and the morphed wing.

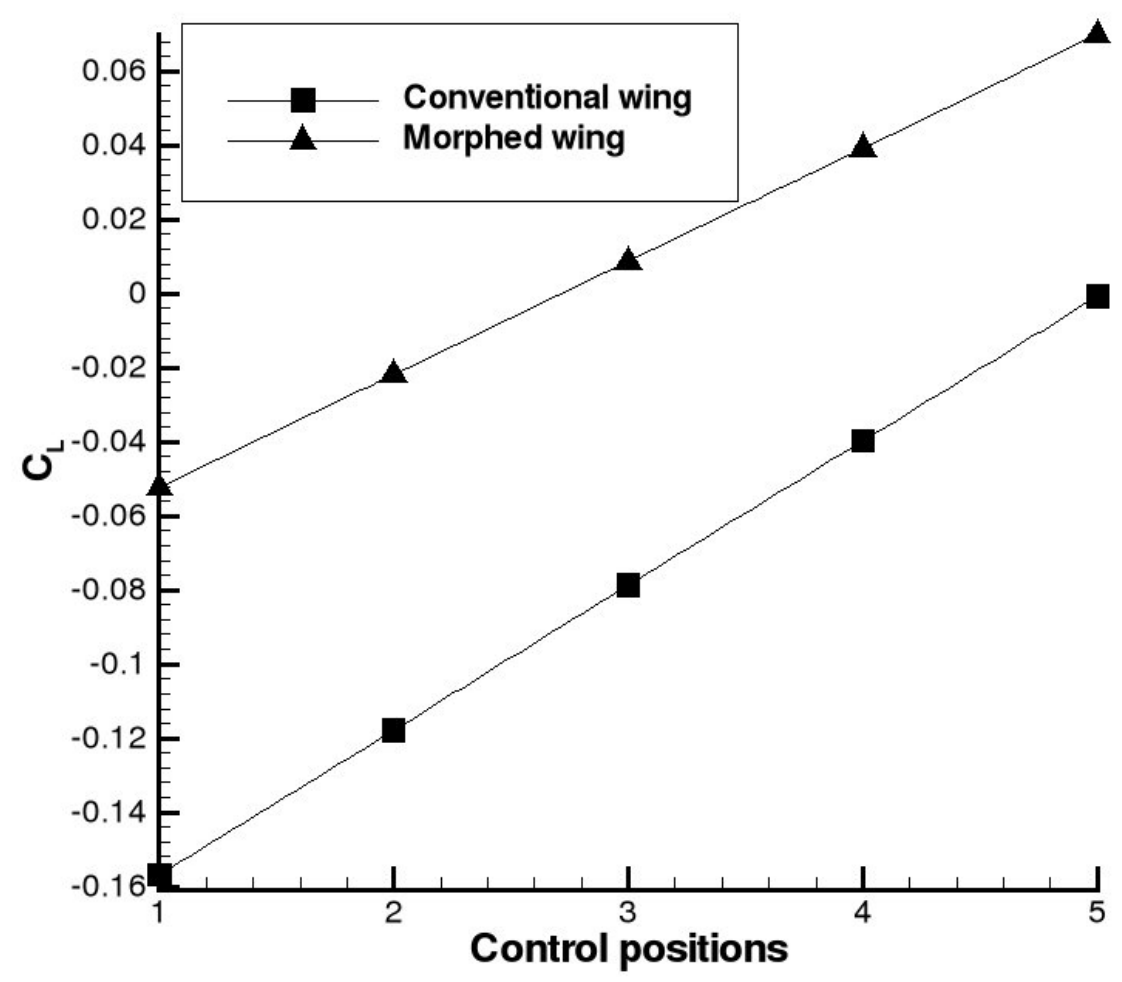

Figure 5.3: Comparison of conventional and morphed wing $C_{L}$ 's at $0^{\circ}$ angle of attack

Since all the analyses in CMARC were inviscid in nature the drag calculated by the code is exclusively induced drag, also computed using the Trefftz plane analysis. Figure 5.4 shows the induced drag coefficients at all five control positions at $0^{\circ}$ angle of attack. It can clearly be seen that the morphed wing has lower induced drag at the outer $33 \%$ of the wing span, which corresponds with the primary region of morph. Similar characteristics are observed at various angles of attack.

As expected the induced drag of the morphed wing at all control positions, except at control position 5, is less than the conventional wing Figure 5.5. At control position 

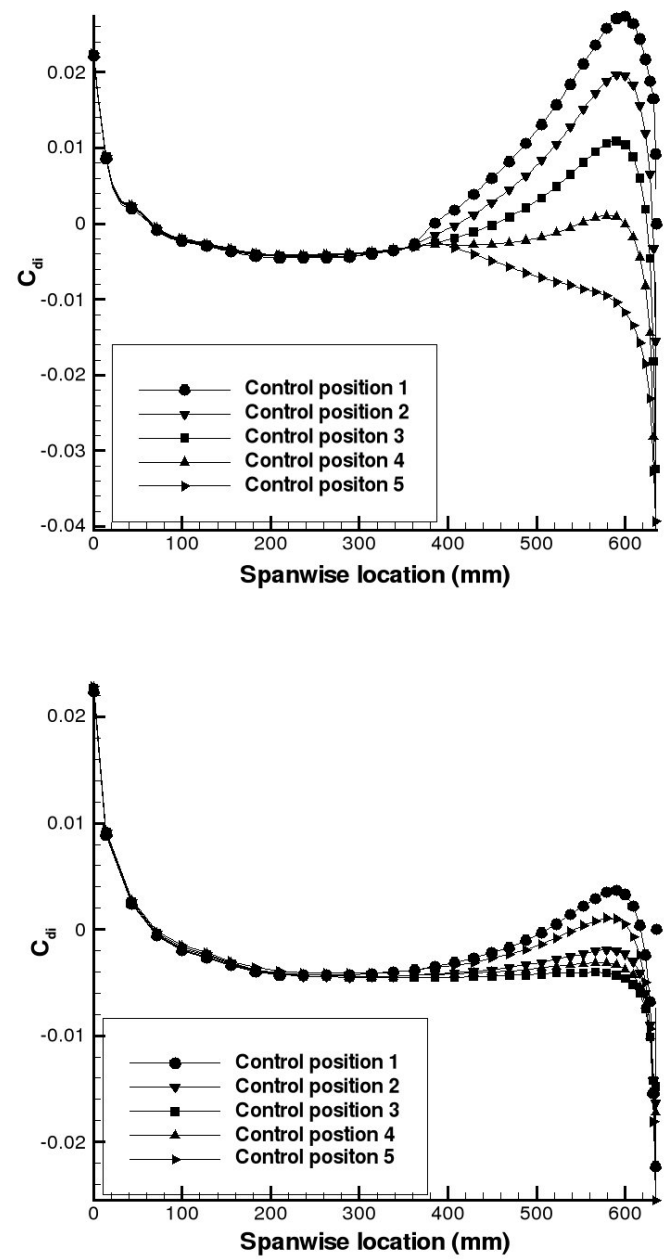

Figure 5.4: Sectional induced drag at various control positions and $0^{\circ}$ angle of attack for conventional(top)and morphed wing (bottom) 


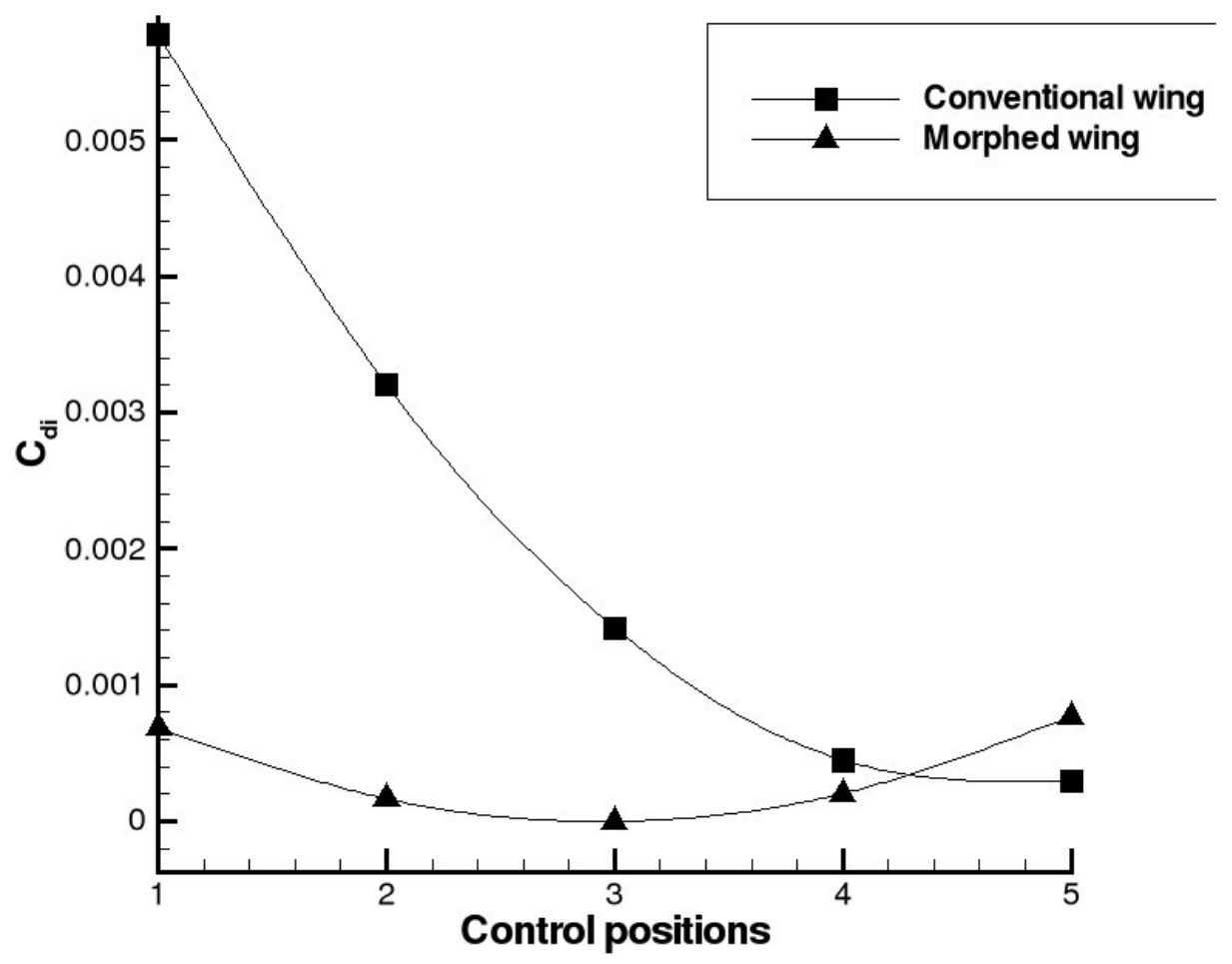

Figure 5.5: Comparison of conventional wing and morphed wing $C_{D_{i}}{ }^{\text {'s }}$ at $0^{\circ}$ angle of attack 
5 the effective twist of the conventional wing is lower than that of the morphed wing due to the built in washout of the conventional wing. Thus the effective twist of the morphed wing is more at this control position compared to the conventional wing.
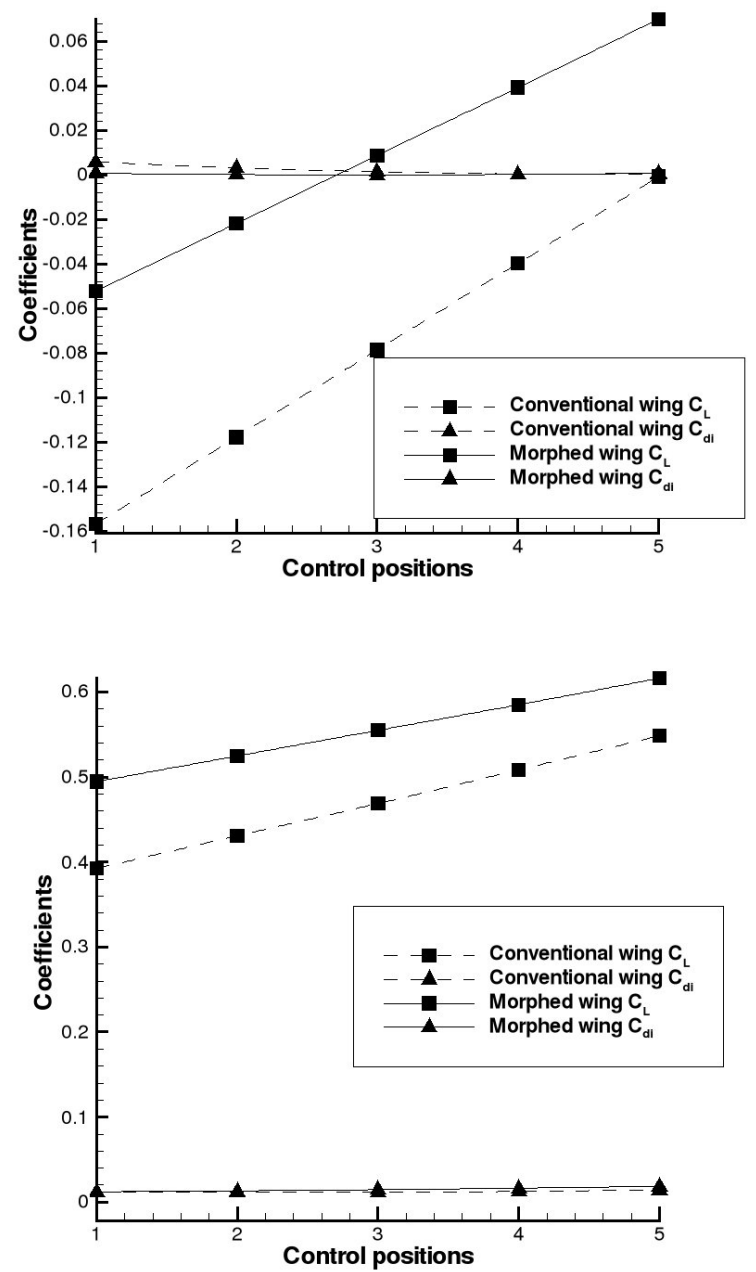

Figure 5.6: Comparison of $C_{L}$ 's and $C_{d_{i}}$ 's at $0^{\circ}$ (top) and $7^{\circ}$ (bottom) angle of attack

Figure 5.6 shows the lift and the induced drag coefficients of both the conventional wing and the morphed wing at $0^{\circ}$ and $7^{\circ}$ angle of attack. At both these angles the lift performance of the morphed wing outperforms the conventional wing as mentioned in Table 5.1. 
Table 5.1: Percent increase in $C_{L}$ 's of morphed wing compared to conventional wing at $7^{\circ}$ angle of attack

\begin{tabular}{|c|c|}
\hline Control positions & \% increase in $C_{L}$ of morphed wing \\
\hline 1 & 25.9 \\
2 & 21.8 \\
3 & 18.3 \\
4 & 15.0 \\
5 & 12.3 \\
\hline
\end{tabular}

\subsubsection{Moment coefficients}

The following section deals with the moment coefficients predicted by CMARC.

Figure 5.7 compares the roll, pitch and yaw moments of the morphed wing and the conventional wing at $0^{\circ}$ and $7^{\circ}$ angle of attack, respectively. Notice that the roll moment at $0^{\circ}$ angle of attack is negative due to the fact that roll moment, which is heavily influenced by lift, is negative at $0^{\circ}$ angle of attack. The opposite can be observed at $7^{\circ}$ angle of attack. In both the cases the yaw moments are quiet similar. Yaw which primarily depends on drag is limited to induced drag in these cases.

In Figure 5.8, which exclusively plots the yawing moments, the yaw at $7^{\circ}$ angle of attack is very different from the yaw profile at $0^{\circ}$ angle of attack; this is due to the fact that as the angle of attack increases the parasitic drag increases. Since CMARC does not capture the parasitic drag the profiles are very different. It is however interesting to note that the yaw moments for the morphed wing at all control positions at $7^{\circ}$ angle of attack are significantly lower than that of the conventional wing with elevons. This is favorable for the morphed wing, as it means that there is a lesser adverse yaw component acting. In theory as predicted by the Hortens [21] the yaw should be negative to help alleviate the adverse yaw effect and aid in the proper turning direction. In this case it can be observed that at control position 5 the yaw is negative, thus confirming the theory to a certain extent. It should be more pronounced in the experimental results, since the drag profiles account for both induced as well as parasitic drag.

Since CMARC is better at calculating the $C_{l}$ s $\mathrm{s}$ as compared to $C_{d}$ ss, the coefficients of roll should theoretically have better similarity to the actual roll coefficients. 

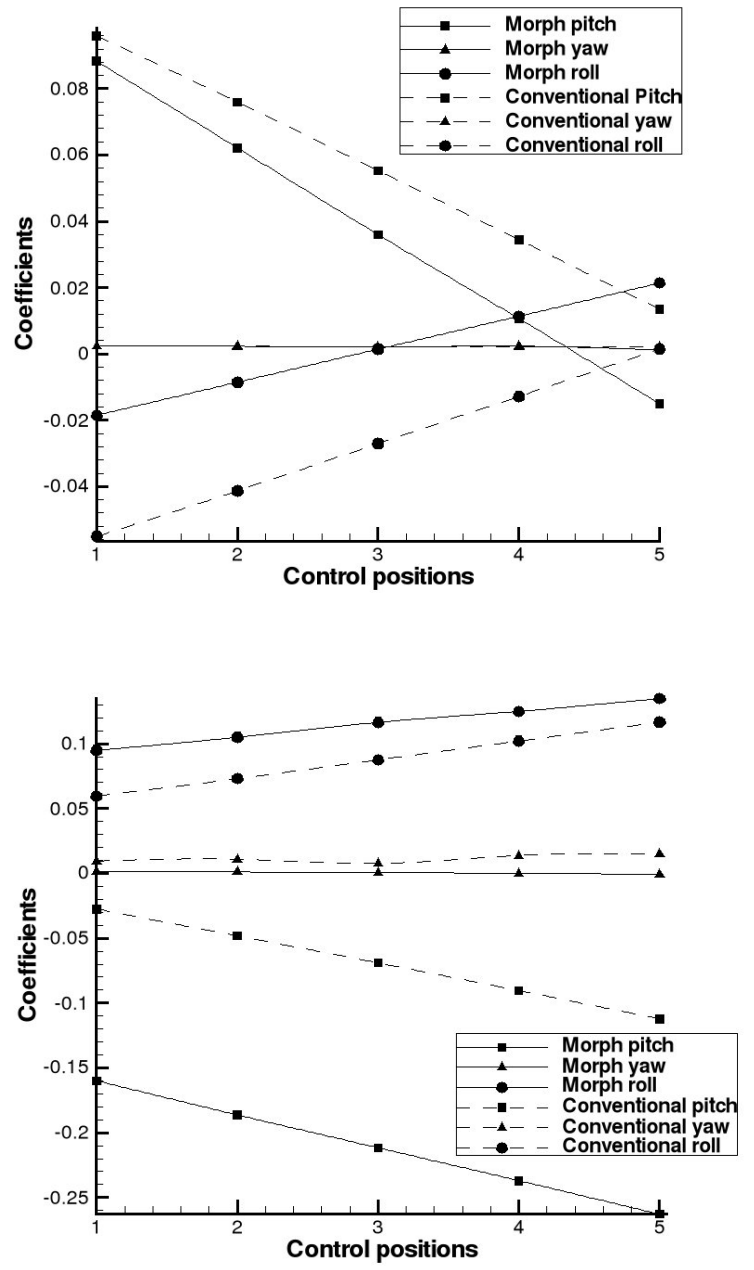

Figure 5.7: Comparison of moment coefficients at $0^{\circ}$ (top) and $7^{\circ}$ (bottom) angle of attack 

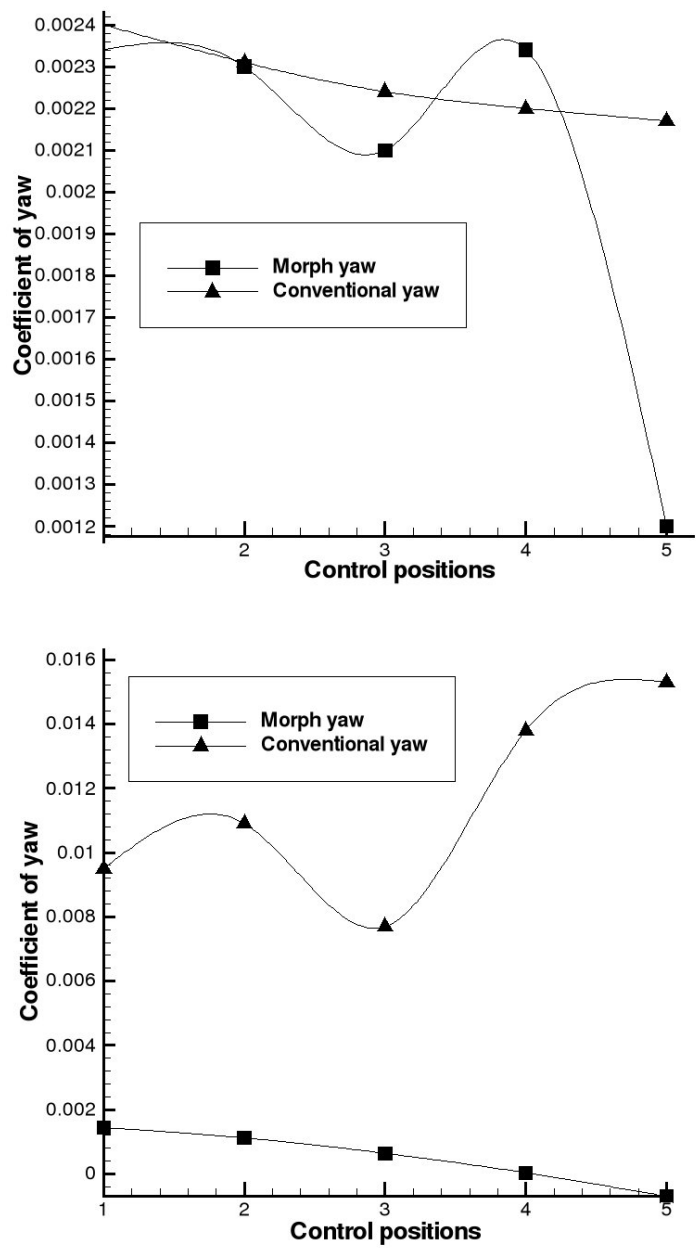

Figure 5.8: Comparison of yawing coefficients at $0^{\circ}$ (top) and $7^{\circ}$ (bottom) angle of attack 
Figure 5.9 plots the roll moment coefficients at $0^{\circ}$ and $7^{\circ}$ angle of attack; the morphed wing has higher roll coefficients compared to the convetional wing at both the angles of attack.
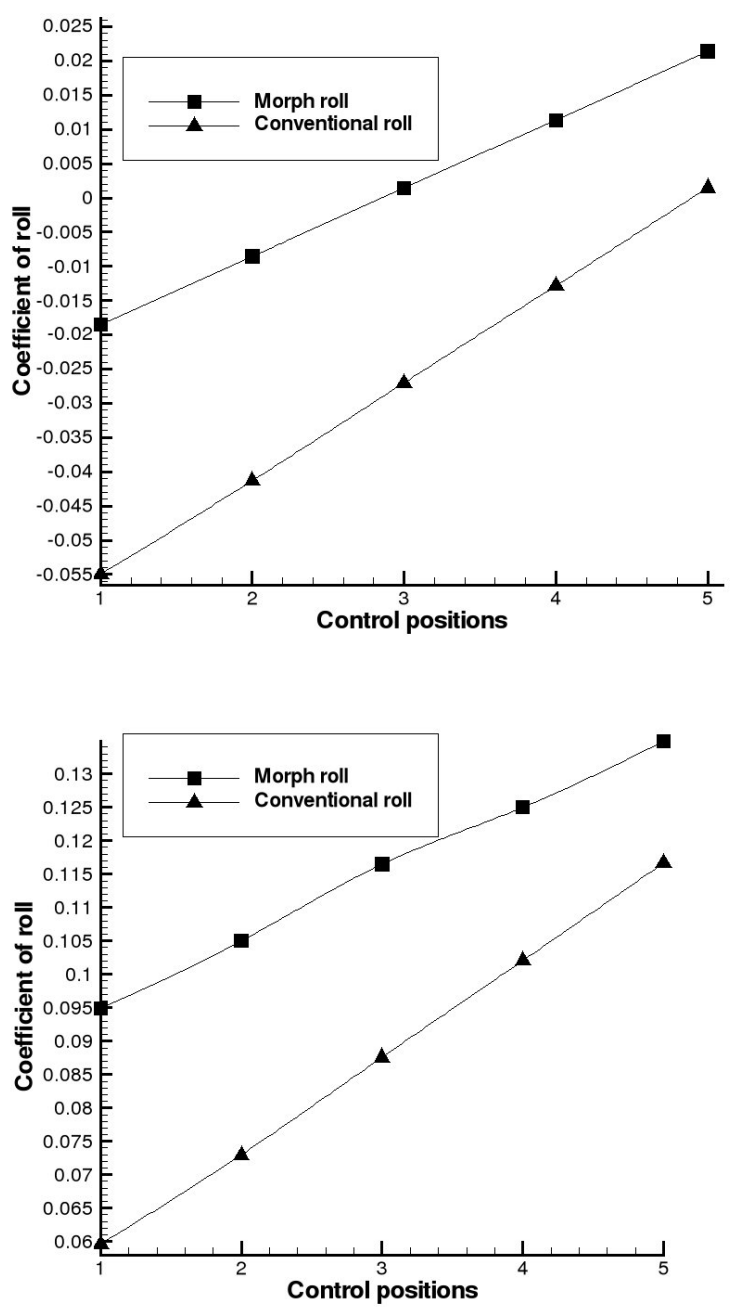

Figure 5.9: Comparison of rolling coefficients at $0^{\circ}$ (top) and $7^{\circ}$ (bottom) angle of attack 


\subsubsection{Wake region}

CMARC has the ability to shed wakes from a user defined line. For the present analysis all the wakes were shed from the trailing edge of the conventional wing as well as for the morphed wing. The following figures 5.10, 5.11, 5.12, show the wakes shed at all five control positions at a $7^{\circ}$ angle of attack. The figure is viewing the wing geometries from the front, with the wake regions proceeding into the plane of the paper.

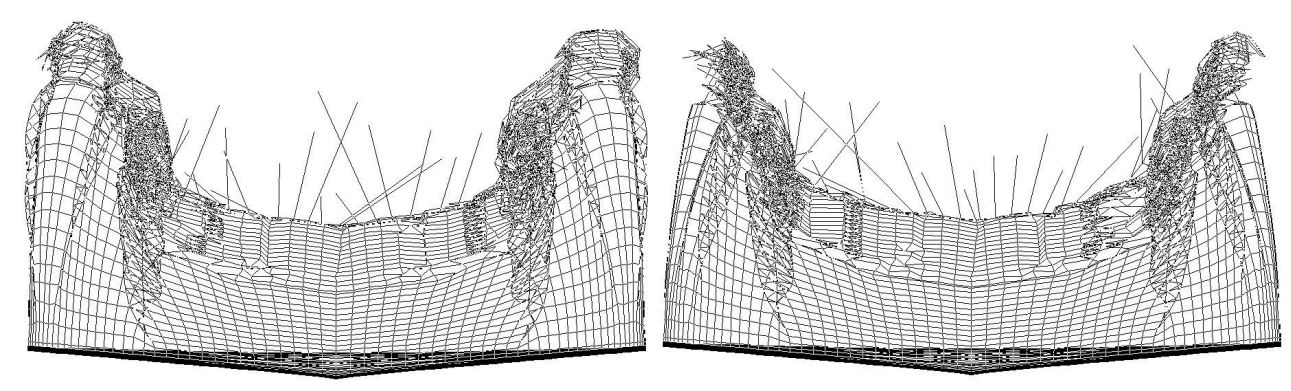

Figure 5.10: Control positions 1 (left) and 2 (right) of conventional wing
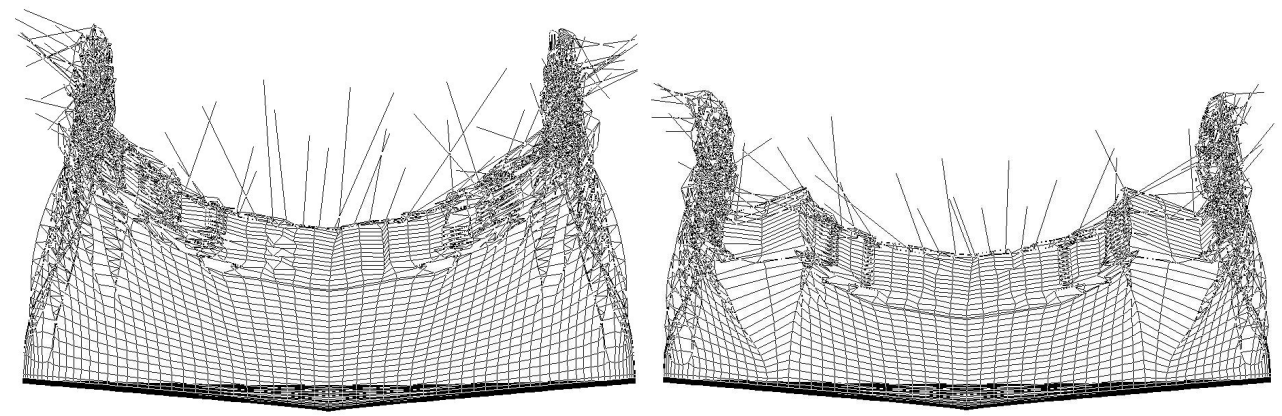

Figure 5.11: Control positions 3 (left) and 4 (right) of conventional wing

Wing tip vortices are shed as the pressures on the lower and the upper surface try to reach equilibrium at the wing tip. On careful observation it is noted that at control position 1 the tip vortices actually reverse themselves briefly. Further investigation of this was done by plotting the $C_{p}$ at the wing tips. Notice in figure 5.14 that at control position 1 the lower surface has a Cp value lower than the upper surface, which results in the wrapping of the wing tip vortex in the opposite direction as compared to the 


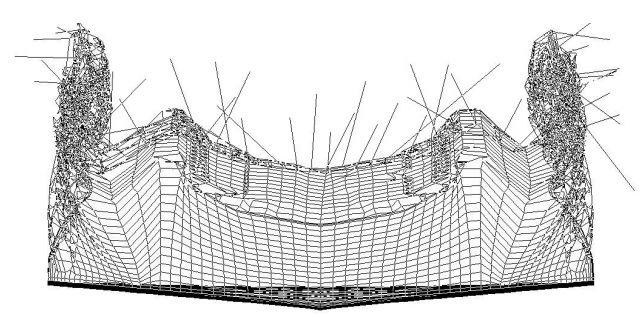

Figure 5.12: Control position 5 of conventional wing

other control positions.

Similar wake profiles have been observed for the morphed wing. Figures 5.15, $5.16,5.17$, show the wake profiles for the morphed wing at $7^{\circ}$ angle of attack.
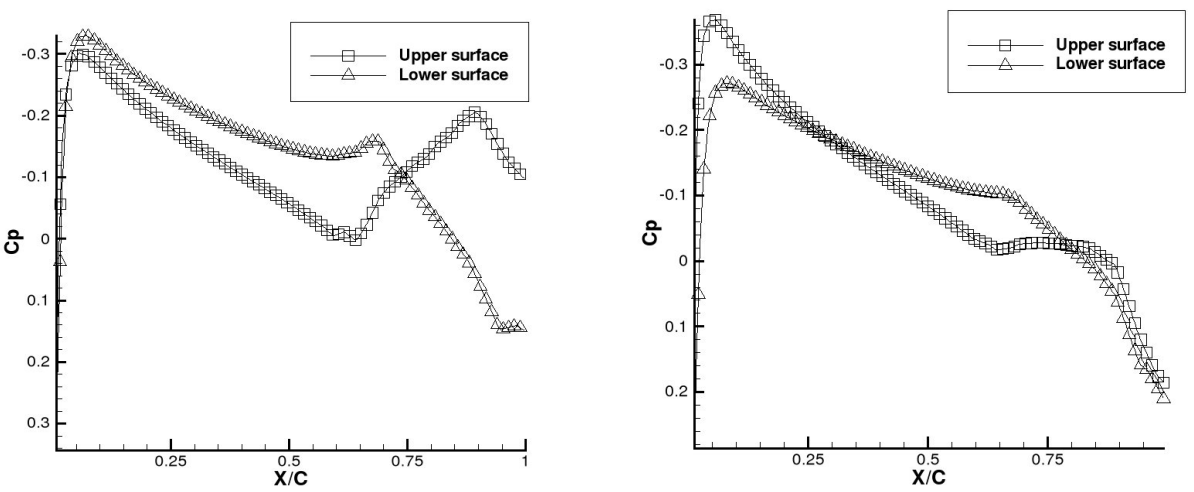

Figure 5.13: Cp at control positions 1 (left) and 2 (right) of conventional wing 

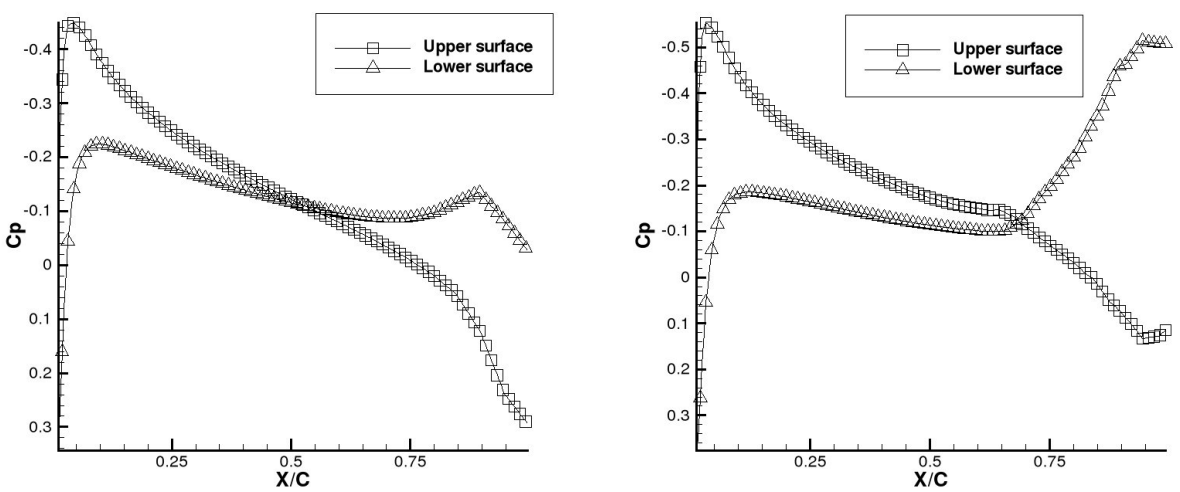

Figure 5.14: Cp at control positions 3 (left) and 4 (right) of conventional wing
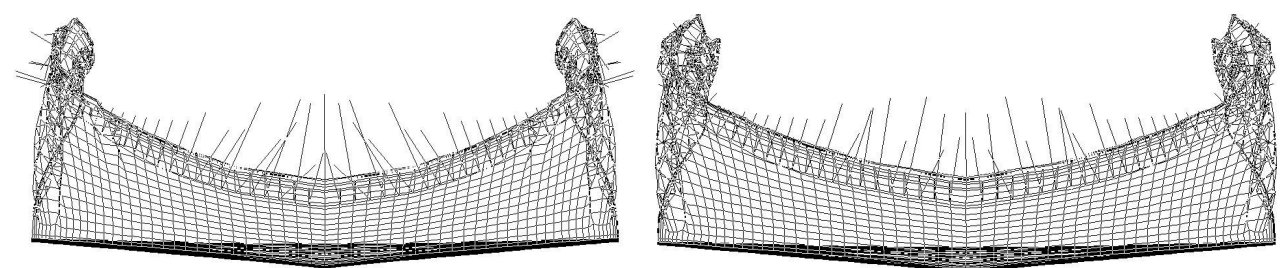

Figure 5.15: Control positions 1 (left) and 2 (right) of morphed wing
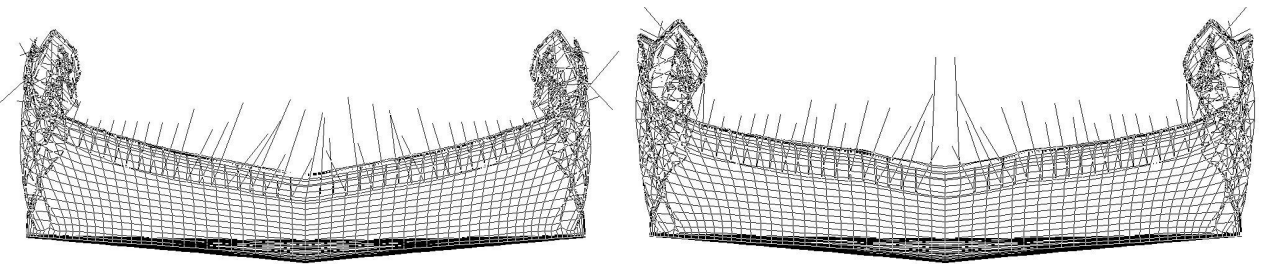

Figure 5.16: Control positions 3 (left) and 4 (right) of morphed wing

Notice however that the reversal of the flow is not observed in any of the control positions of the morphed wing. This however was observed in the experiment, as will be discussed in the next section. 


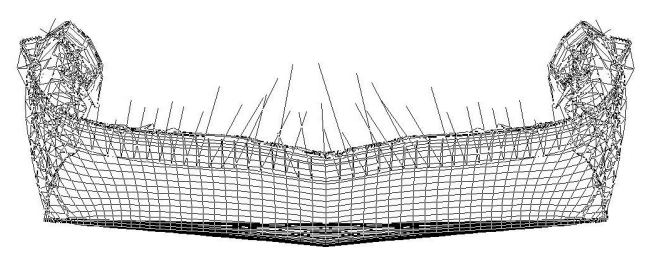

Figure 5.17: Control position 5 of morphed wing

\subsection{Comparison of Experimental and CMARC re- sults}

Once the results were obtained with CMARC, the next step was to compare these results obtained using CMARC to the actual experimental results. Also it would be interesting to see if some of the tip vortices being formed on CMARC could be actually viewed.

Figure 5.18 compares the coefficients of lift and induced drag from CMARC to actual lift and drag obtained in the experiments for $0^{\circ}$ angle of attack. It can be seen that there is good agreement of trends of in the case of the morphed wing. The $C_{L}$ 's do not match well in the case of the conventional wing especially at control position 1. Table 5.2 gives the percent difference of $C_{L}$ between CMARC and experimental results at $0^{\circ}$ angle of attack.

Table 5.2: Percent difference in $C_{L}$ 's between experimenatal and computed results for conventional and morphed wings at $0^{\circ}$ angle of attack

\begin{tabular}{|c|c|c|}
\hline Control Positions & \% difference for conventional wing & \% difference for morphed wing \\
\hline 1 & 31.7 & 70.42 \\
2 & 54.3 & 83.9 \\
3 & 65.0 & 88.0 \\
4 & 53.2 & 12.7 \\
5 & 99.1 & 22.71 \\
\hline
\end{tabular}

Figure 5.19 compares experimantal and CMARC results at $3.5^{\circ}$ angle of attack. The $C_{L}$ plots for the morphed wing are in better agreement compared to the conventional wing. This could possibily be due to separation of flow at the elevons that 

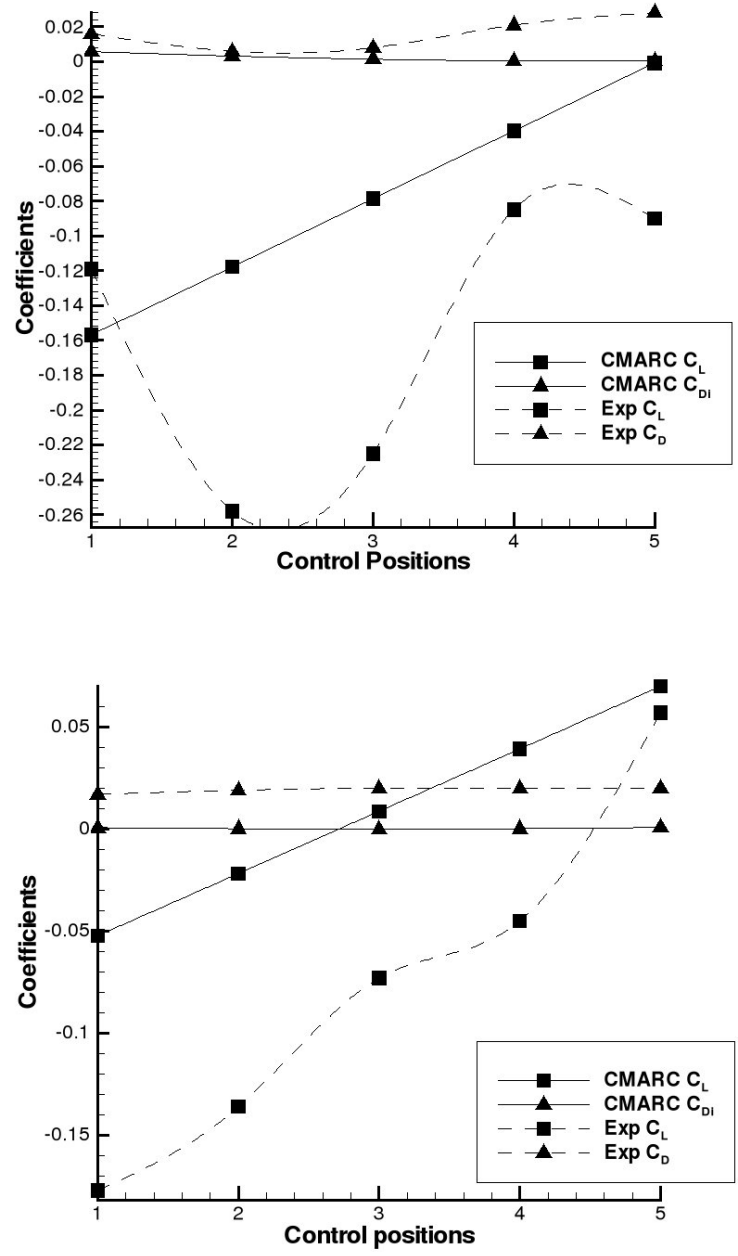

Figure 5.18: Comparison of experimental and CMARC results for conventional (top) and morphed wings (bottom) at $0^{\circ}$ angle of attack 
cannot be captured by CMARC. This in turn results in a low $C_{L}$ for the experimental conventional wing, whereas CMARC overpredicts the $C_{L}$.
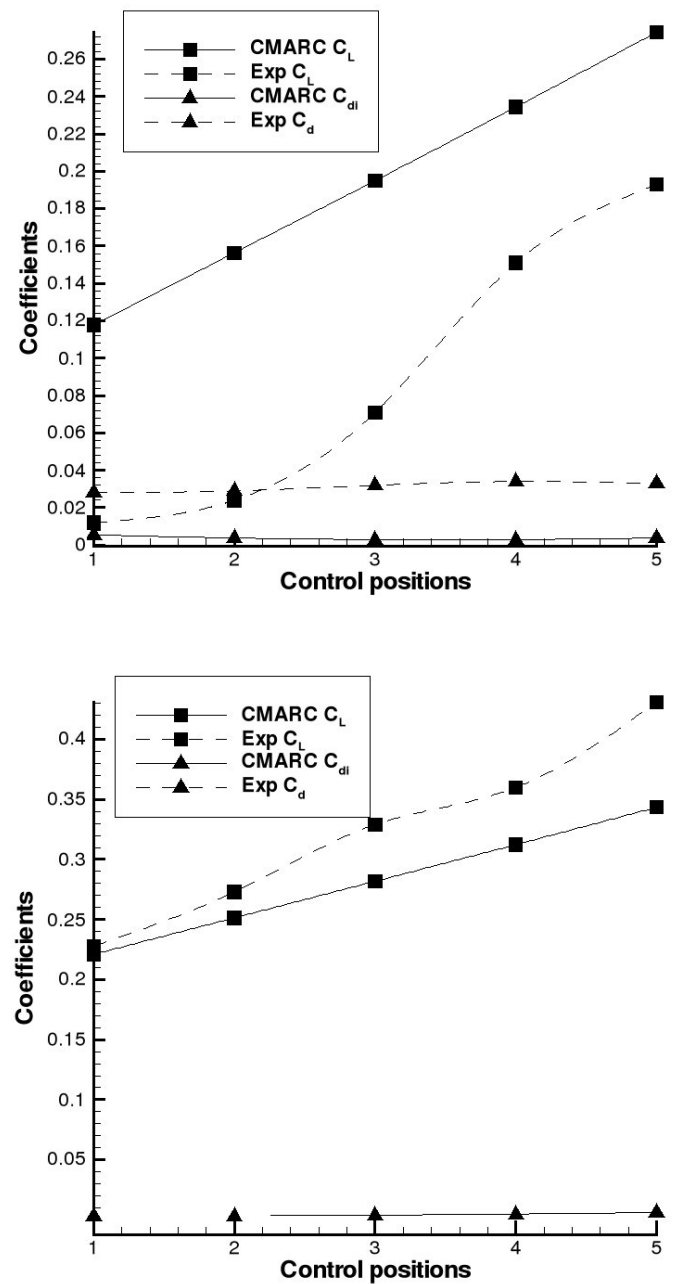

Figure 5.19: Comparison of experimental and CMARC results for conventional (top) and morphed wings (bottom) at $3.5^{\circ}$ angle of attack

The agreement between experimental results and that obtained by CMARC are very good at $7^{\circ}$ angle of attack, Figure 5.22. As expected the values predicted by CMARC are higher compared to the experimental values. This is because CMARC overpredicts the lift as there are not viscous effects considered. Notice in Figure 5.20 that the disagreement is larger in the case of the morphed wing compared to the conventional wing. Table 5.3 gives the percentage difference of experimental $C_{L}$ to 

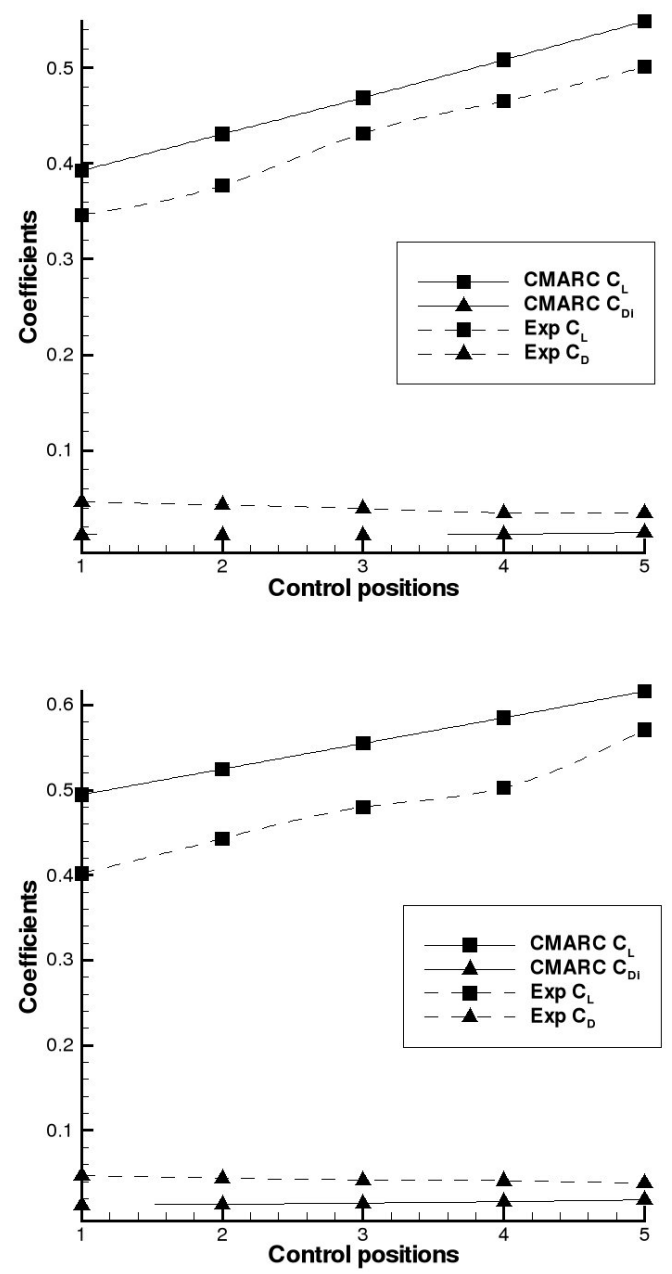

Figure 5.20: Comparison of experimental and CMARC results for conventional (top) and morphed wings (bottom) at $7^{\circ}$ angle of attack 
computed $C_{L}$ at $7^{\circ}$ angle of attack .

Table 5.3: Percent difference in $C_{L}$ 's between experimental and computed results for conventional and morphed wing at $7^{\circ}$ angle of attack

\begin{tabular}{|c|c|c|}
\hline Control Position & \% difference for conventional wing & \% difference for morphed wing \\
\hline 1 & 13.2 & 23.0 \\
2 & 14.2 & 18.4 \\
3 & 8.5 & 15.5 \\
4 & 9.2 & 16.3 \\
5 & 9.5 & 7.9 \\
\hline
\end{tabular}

At $0^{\circ}$ angle of attack the rolling moment and the pitching moment shown in Figure 5.21, are not in very good agreement. This is due to the fact that rolling moment largely depends on the $C_{L}$ 's predicted by CMARC which also at $0^{\circ}$ angle of attack is not in very good agreement with the experimental results for the conventional wing only. There is reasonable agreement in case of the morphed wing. Notice that the yawing coefficient in case of the experimental morphed wing is largely negative, that way avoiding effects of adverse yaw.

Again at $7^{\circ}$ angle of attack CMARC performs relatively well to predict the moments (Figure 5.22); the trends are very similar to the experimental results.

Figure 5.23 compares the yaw an roll coefficients at $7^{\circ}$ angle of attack for the conventional and morphed wings to the experimental studies. The trends for the roll moment coefficients are in agreement with the experimental results. Yaw moments however are a little awry. 

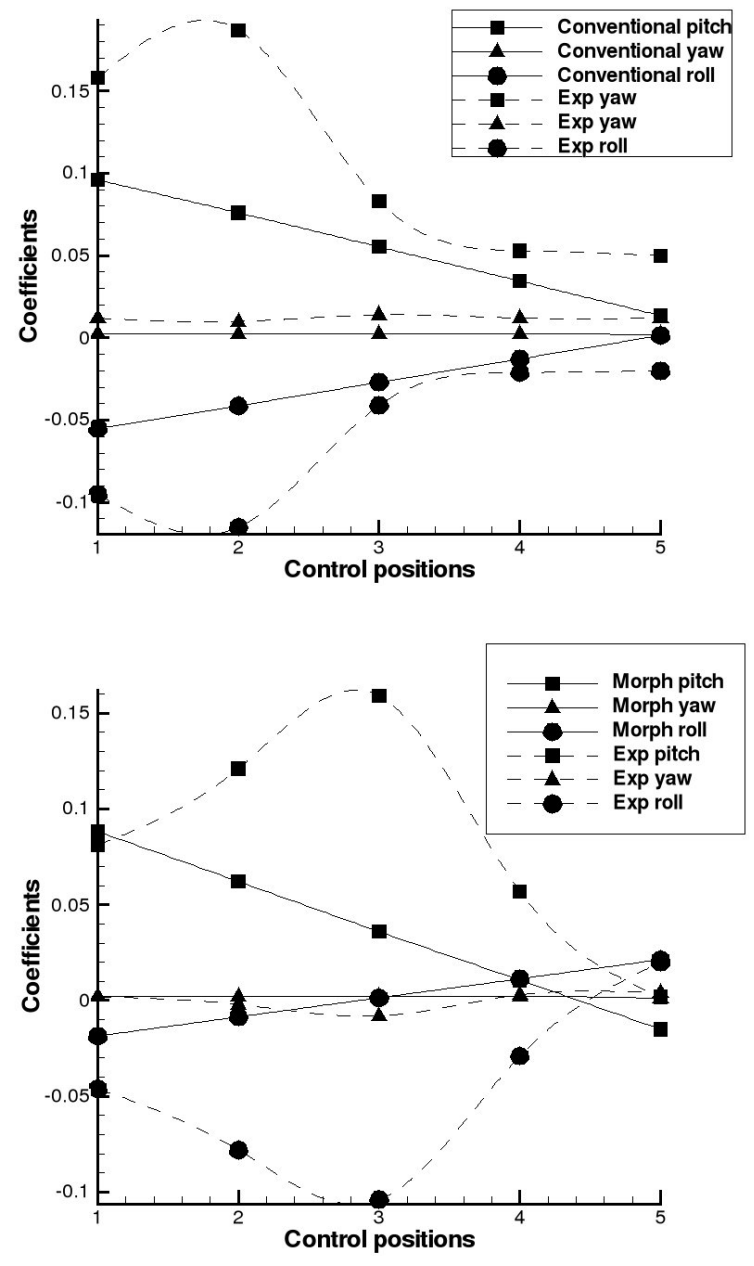

Figure 5.21: Comparison of experimental and CMARC moment coefficients at $0^{\circ}$ angle of attack for conventional (top) and morphed (bottom) wing 

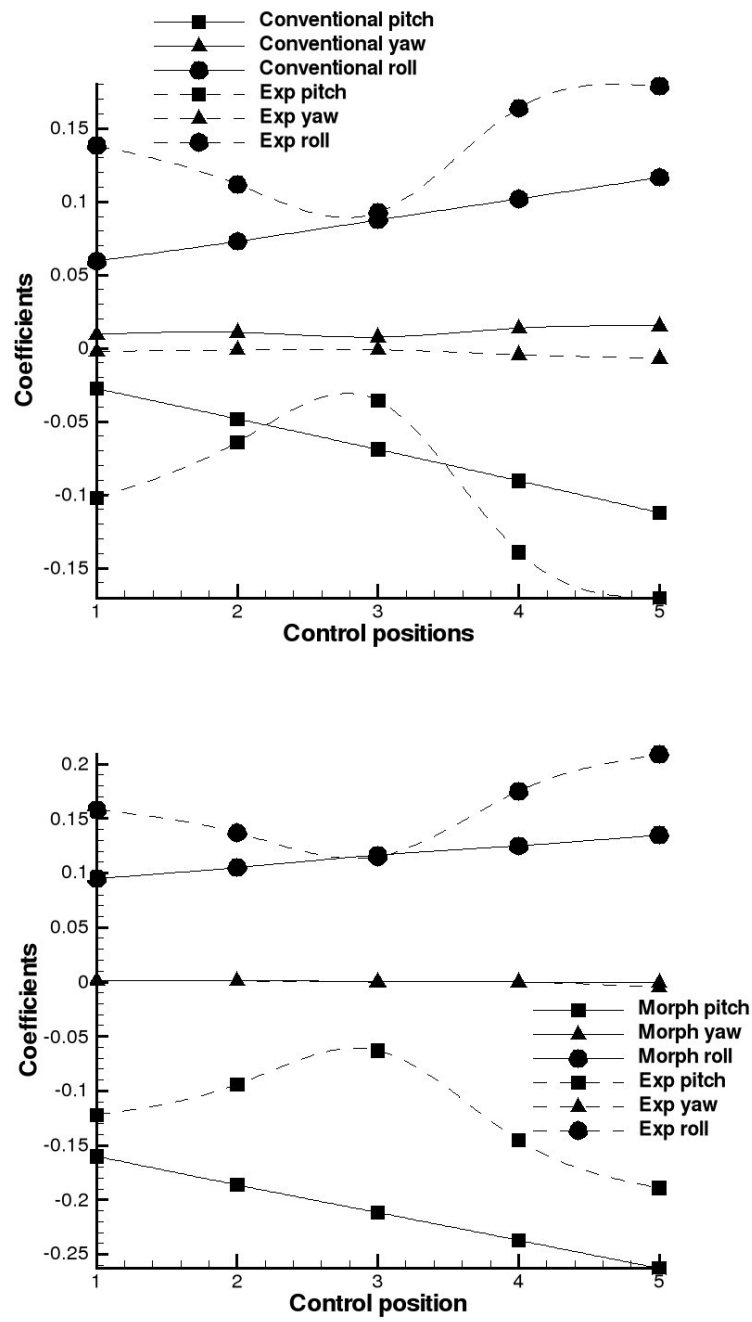

Figure 5.22: Comparison of experimental and CMARC moment coefficients at $7^{\circ}$ angle of attack for conventional (top) and morphed (bottom) wings 

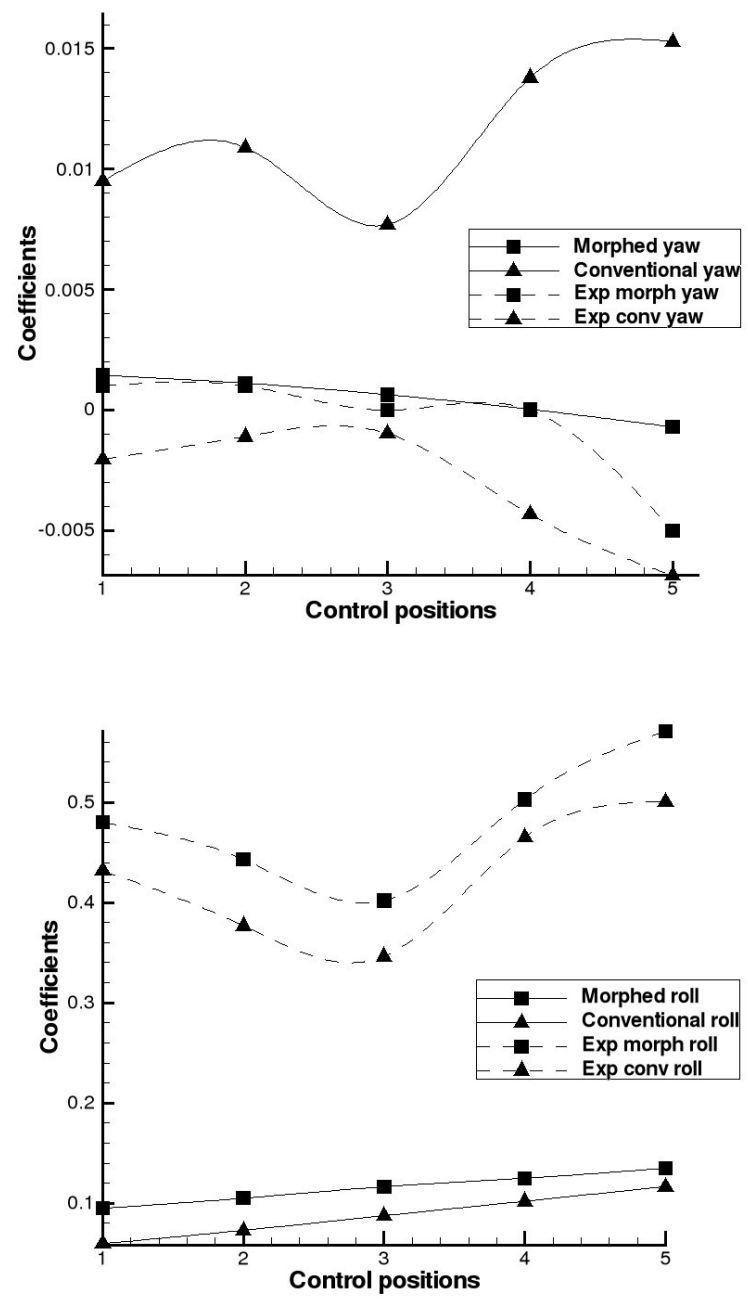

Figure 5.23: Comparison of experimental and CMARC results for yaw (top) and roll (bottom) coefficients at $7^{\circ}$ angle of attack 


\section{Chapter 6}

\section{Conclusions}

This research was started out with the objective of analyzing the newly developed morphing wing in a short duration of time without considerable computing expenses. In this regard CMARC has performed reasonably well. Its predictions of $C_{L}{ }^{\text {'s }}$ were inside an error range of $7-23 \%$ for the morphed wing and $8-14 \%$ for a conventional wing at various control positions. CMARC does not perform very well with the drag prediction as expected. A very interesting thing to notice is that at control position 5 the percent difference in predicted values to experimental values are the highest in both the $C_{L}$ 's and $C_{D_{i}}$ ss. Control position 5 corresponds to a positive twist of $7^{\circ}$ at the wing tip. A possible explanation of behavior is the onset separation at the wing tip. This cannot be captured by CMARC, so rightfully the percent difference of the conventional wing is $13 \%$ and that for the morphed wing is $23 \%$. This is due to the built in washout in the conventional wing. The percent difference in $C_{L}$ at $3.5^{\circ}$ angle of attack is lesser in case of the morphed wing compared to the conventional wing. This again can be attributed to the fact that the conventional wing has elevons which can lead to the onset of turbulence.

Although CMARC is not able to predict the removal of the adverse yaw component, like the experimental results, it is however very close to the value. The overall moment characteristics were well predicted by CMARC. It is also observed that CMARC seems to perform well at higher angles of attack. This conclusion however cannot be true since at higher angles of attack CMARC fails to capture turbulence 
or separation effects. Thus the high percent difference observed in $C_{L}$ at $0^{\circ}$ angle of attack can be attributed to human error where the angle was actually not $0^{\circ}$.

CMARC is successful in detecting the reversal of tip vortices, which was also observed in the experiment for the conventional wing. In the case of the morphed wing, the tip vortex was observed between control positions 1 and 2 . This however was not observed by CMARC, which could be due to the fact that the morphed wing underwent significant geometric changes after the modeling and analysis was performed.

A very interesting phenomenon observed during experimentation was that at control position 5 which corresponded to the maximum $C_{L}$, unexpectedly the lowest $C_{d}$ and negative yaw were observed. This behavior was attributed to the Reynolds number dependency of the flow, which unfortunately cannot be captured by CMARC.

Overall it can be concluded that CMARC is an extremely fast way to get an appropriate estimate of $C_{L}$ 's. It can also be stated with a degree of confidence that the performance of the morphed wing was superior compared to the conventional wing for the conditions tested. 


\section{References}

[1] Northrop John K., "The development of All-Wing aircraft" 35th Wilbur Wright Memorial lecture, London, May 29, 1947.

[2] Dezso George-Falvy, A Review of Aerodynamic Evaluation Tests of the Horten IVa Flying Wing, Presented at the National Soaring Museum Wing Symposium, Elmira, NY, July 17, 1997.

[3] Horten Reimar and Selinger Peter, "Nurflugel-Die geschichte der Horten-Flugzeuge 1933- 1960", H. Weishaupt verlag, Graz, Austria, 1993.

[4] http://www.nurflugel.com

[5] http://wright.nasa.gov/airplane/warp.html

[6] R. W. Wlezien, G. C. Homer, A. R. McGowan, S. L. Padula, M. A. Scott, R. J. Silcox, and J. O. Simpson., NASA Langley Research Center, Hampton, VA "The aircraft morphing program", 39th structures, structural dynamics, and materials conference and exhibit, Long Beach,California, 1998.

[7] Jennifer P. Florance, Alpheus W. Burner, Gary A. Fleming, Craig A. Hunter, and Sharon S. Graves, NASA Langley Research Center Hampton, VA 23681, Christopher A. Martin, Northrop Grumman Corporation, El Segundo, CA 90245, "Contributions of the NASA Langley Reseach Center to the DARPA/AFRL/NASA/Northrop Grumman smart wing program", AIAA Dynamics Specialists Conference, Norfolk 
VA, 2003.

[8] Chatlynne E., Rumingway N., Amitay M., and Glezer ,A., "Virtual aero-shaping of a Clark-Y airfoil using synthetic jet actuators", AIAA paper 200-2401, 2000.

[9] Chen Fang-Jenq and Beeler.B George ,"Virtual shaping of a two dimensional NACA 0015 airfoil using synthetic jet actuators" , AIAA2002-3273.

[10] Garcia H. M., Abdulrahim M., and Lind R., Roll Control for a Micro Air Vehicle Using Active Wing Morphing, University of Florida, AIAA paper AIAA-2003-5347, 2003.

[11] Richard Guiler and Dr. Wade Huebsch, " Development and Testing of a Wing Morphing Mechanism for the Control of a Swept Wing Tailless aircraft", SAE technical papers , 2005-01-3391.

[12] Hepperle Martin, "Airfoil Design for Light Tailless Airplanes", http://www.mh-aerotools.de/airfoils.htm, 2004.

[13] Principles of Ideal-Fluid Aerodynamics, Karamcheti Krishnamurty, John Wiley and Sons, Inc, New York.

[14] Dale L. Ashby, Michael Dudley, Steven K. Iguchi, "Potential flow theory and operation guide for the Panle code PMARC" Ames Research Center, Moffett Field, California .

[15] www.areologic.com

[16] www.areologic.com

[17] www.areologic.com

[18] Theory of Wing Sections, Ira H. Abbott, Albert E. Von Doenhoff, Dover Publications, Inc, New York.

[19] http://www.nps.navy.mil/avsafety

[20] Trefftz E, Prandtlsche Tragflachen-und Propeller-Theorien. Z. Angew Math. Mech., vol. 1, 1921, p. 206.

[21] Reimar Horten, "Toward the theory of Flying Wings-the idea". 


\section{Appendix A}

\section{CMARC input data}

The followig table is an example of a * .sd file created on Loftsman. The present table is that of a NACA0010 section.

\begin{tabular}{|r|r|}
\hline @crd & \\
\hline 1 & \\
\hline @tcrat & \\
\hline 0.09994 & \\
\hline @coords & \\
\hline 1 & 0 \\
\hline 0.997069 & 0.001572 \\
\hline 0.98831 & 0.002236 \\
\hline 0.973827 & 0.004127 \\
\hline 0.953788 & 0.006279 \\
\hline 0.928429 & 0.009062 \\
\hline 0.898047 & 0.012262 \\
\hline 0.862998 & 0.015817 \\
\hline 0.823693 & 0.019636 \\
\hline 0.780594 & 0.023625 \\
\hline 0.734204 & 0.027688 \\
\hline 0.685069 & 0.031726 \\
\hline 0.633764 & 0.035635 \\
\hline 0.580891 & 0.039307 \\
\hline
\end{tabular}




\begin{tabular}{|r|r|}
\hline 0.527069 & 0.042625 \\
\hline 0.472931 & 0.045468 \\
\hline 0.419109 & 0.047717 \\
\hline 0.366236 & 0.049252 \\
\hline 0.314931 & 0.04997 \\
\hline 0.265796 & 0.049783 \\
\hline 0.219406 & 0.048632 \\
\hline 0.176307 & 0.046489 \\
\hline 0.137002 & 0.043363 \\
\hline 0.101953 & 0.039294 \\
\hline 0.071571 & 0.034354 \\
\hline 0.046212 & 0.028651 \\
\hline 0.026173 & 0.022214 \\
\hline 0.01169 & 0.015381 \\
\hline 0.002931 & 0.007542 \\
\hline 0 & \\
\hline 0.002931 & -0.00754 \\
\hline 0.01169 & -0.01538 \\
\hline 0.026173 & -0.02221 \\
\hline 0.046212 & -0.02865 \\
\hline 0.071571 & -0.03435 \\
\hline 0.101953 & -0.03929 \\
\hline 0.137002 & -0.04336 \\
\hline 0.176307 & -0.04649 \\
\hline 0.219406 & -0.04863 \\
\hline 0.265796 & -0.04978 \\
\hline 0.314931 & -0.04997 \\
\hline 0.366236 & -0.04925 \\
\hline 0.419109 & -0.04772 \\
\hline 0.472931 & -0.04547 \\
\hline 0.527069 & -0.04263 \\
\hline 0.580891 & -0.03931 \\
\hline 0.633764 & -0.03564 \\
\hline 0.685069 & -0.03173 \\
\hline 0.734204 & -0.02769 \\
\hline
\end{tabular}




\begin{tabular}{|r|r|}
\hline 0.780594 & -0.02363 \\
\hline 0.823693 & -0.01964 \\
\hline 0.862998 & -0.01582 \\
\hline 0.898047 & -0.01226 \\
\hline 0.928429 & -0.00906 \\
\hline 0.953788 & -0.00628 \\
\hline 0.973827 & -0.00413 \\
\hline 0.98831 & -0.00224 \\
\hline 0.997069 & -0.00157 \\
\hline 1 & 0 \\
\hline @end & \\
\hline & \\
\hline
\end{tabular}

The following is an example of a ${ }^{*}$.wi file in CMARC. The example is that of a Morphed wing at control position1.

\section{WING LOFT}

Date: $1 / 13 / 06$

Breaks: 3

Break 1

Axis: $64.1520,0.0000,0.0000$

Axis/chord: 0.1787

Chord: 358.8800

Incidence: 0.0000

Cant: 0.0000

Section file: MH7819

$\mathrm{T} / \mathrm{C}$ ratio: 0.0005

Spars: 0

Panel rib angles: 0.0000,999.0000,0.0000

Break 2

Axis: $162.3476,158.5000,11.0000$

Axis/chord: 0.2036

Chord: 252.2000

Incidence: 0.0000

Cant: 0.0000

Section file: MH7814

$\mathrm{T} / \mathrm{C}$ ratio: 0.0006

Spars: 0 
Panel rib angles: 0.0000,999.0000,0.0000

Break 3

Axis: $460.0000,636.0000,44.4000$

Axis/chord: 0.2511

Chord: 58.4020

Incidence: 0.0000

Cant: 0.0000

Section file: NACA0010

$\mathrm{T} / \mathrm{C}$ ratio: 0.0017

Spars: 0

Panel rib angles: 0.0000,999.0000,0.0000

The following is a ${ }^{*}$.in file for the NACA 001o benchmarking test case.

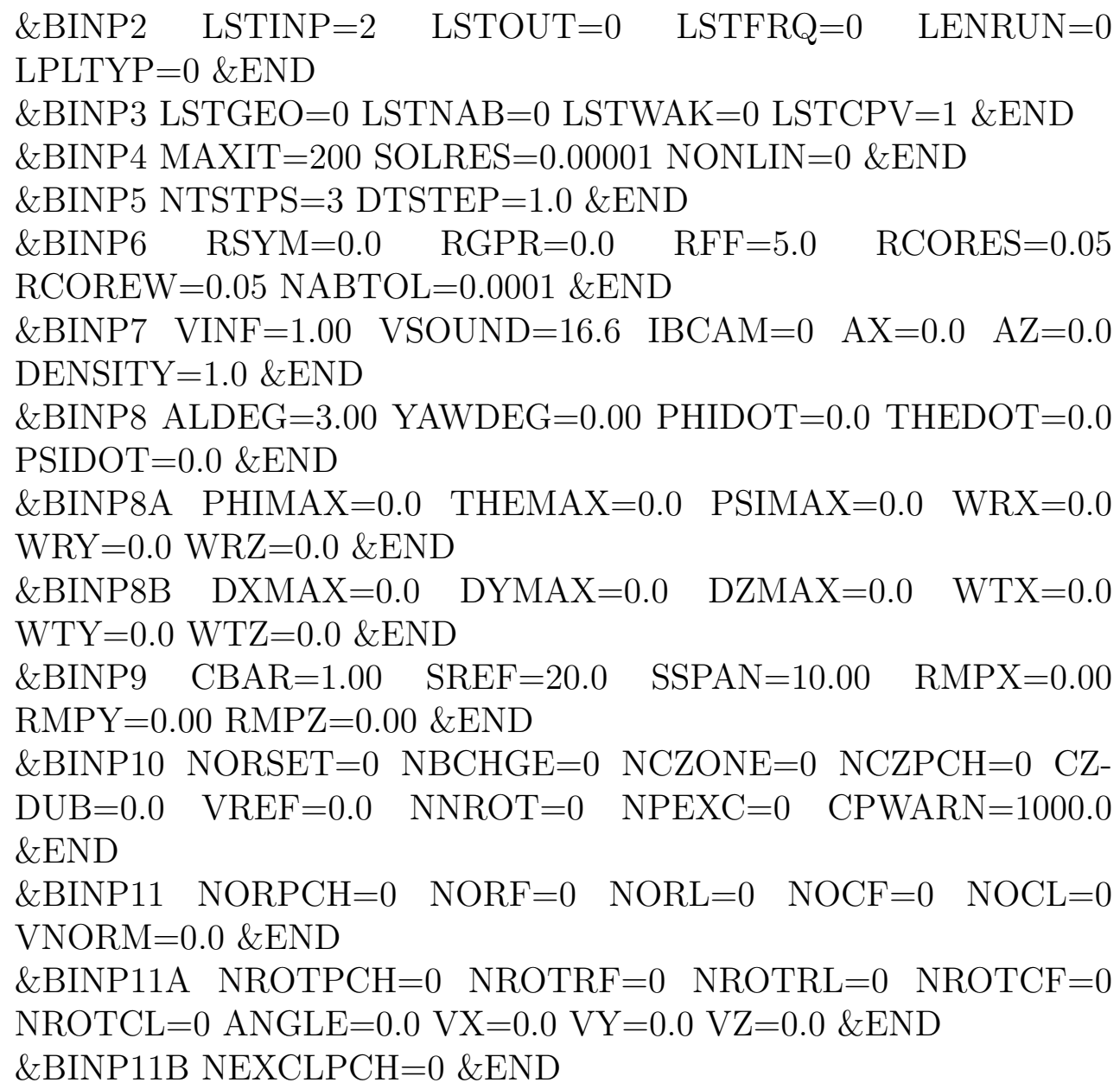


$\& B I N P 12$ KPAN $=0$ KSIDE $=0$ NEWNAB $=0$ NEWSID $=0 \& E N D$ $\& B I N P 13$ NBLIT $=1 \&$ END

\&BINP14 MAXIT $=15 \quad$ NLTOL $=0.01 \quad$ CONTINUE $=1 \quad$ KEEP $=0$ $\mathrm{RN}=1000000 \quad \mathrm{KVISC}=0.02304 \quad \mathrm{MINCP}=-15.0 \quad \mathrm{MAXCP}=15.0 \quad \mathrm{MAX}-$ $\mathrm{COATS}=50 \mathrm{NMON}=0 \mathrm{MONITOR}=0 \mathrm{NJUMP}=0 \& \mathrm{END}$

$\& B I N P 14 A \quad \mathrm{NJMPPCH}=0 \quad \mathrm{NJMPRF}=0 \quad \mathrm{NJMPRL}=0 \quad \mathrm{NJMPCF}=0$ $\mathrm{NJMPCL}=0$ \&END

\&ASEM $1 \quad$ ASEMX $=0.0 \quad$ ASEMY $=0.0 \quad$ ASEMZ $=0.0 \quad$ ASCAL $=1.0$ ATHET $=0.0$ NODEA $=5 \& E N D$

$\& \mathrm{ASEM} 2 \mathrm{APXX}=0.0 \mathrm{APYY}=0.0 \quad \mathrm{APZZ}=0.0 \quad \mathrm{AHXX}=0.0 \quad \mathrm{AHYY}=0.0$ $\mathrm{AHZZ}=0.0 \& \mathrm{END}$

$\& C O M P 1 \quad \mathrm{COMPX}=0.0 \quad \mathrm{COMPY}=0.0 \quad \mathrm{COMPZ}=0.0 \quad \mathrm{CSCAL}=1.0$ $\mathrm{CTHET}=0.0 \mathrm{NODEC}=5 \& \mathrm{END}$

$\& \mathrm{COMP} 2 \mathrm{CPXX}=0.0 \mathrm{CPYY}=0.0 \mathrm{CPZZ}=0.0 \mathrm{CHXX}=0.0 \mathrm{CHYY}=0.0$ $\mathrm{CHZZ}=0.0 \& \mathrm{END}$

\&PATCH1 $\operatorname{IREV}=0, \mathrm{IDPAT}=1, \mathrm{MAKE}=0, \mathrm{KCOMP}=1, \mathrm{KASS}=1$, IPATSYM $=0$, IPATCOP $=0, \& E N D$

NACA

\&SECT1 STX=-0.2511, STY=0.0, STZ=0.0, SCALE=1.0, ALF=0.0, $\mathrm{THETA}=0.0, \mathrm{INMODE}=4, \mathrm{TNODS}=0, \mathrm{TNPS}=0, \mathrm{TINTS}=0, \& \mathrm{END}$

1.00000 .00000 .0000

$0.97550 .0000-0.0038$

$0.90450 .0000-0.0116$

$0.79390 .0000-0.0224$

$0.65450 .0000-0.0341$

$0.50000 .0000-0.0441$

$0.34550 .0000-0.0496$

$0.20610 .0000-0.0481$

$0.09550 .0000-0.0384$

$0.02450 .0000-0.0216$

0.00000 .00000 .0000

$\&$ BPNODE TNODE $=1, \mathrm{TNPC}=30, \mathrm{TINTC}=0, \& \mathrm{END}$

0.02450 .00000 .0216

0.09550 .00000 .0384

0.20610 .00000 .0481

0.34550 .00000 .0496

0.50000 .00000 .0441

0.65450 .00000 .0341

0.79390 .00000 .0224 
0.90450 .00000 .0116

0.97550 .00000 .0038

1.00000 .00000 .0000

$\&$ BPNODE TNODE $=3$, TNPC $=30$, TINTC $=0, \& E N D$

$\&$ SECT1 STX=-0.2511, STY=10.0, STZ=0.0, SCALE=1.0, ALF=0.0, $\mathrm{THETA}=0.0, \mathrm{INMODE}=0, \mathrm{TNODS}=5, \mathrm{TNPS}=30, \mathrm{TINTS}=2, \& \mathrm{END}$

$\& W A K E 1$ IDWAK $=1$ IFLXW $=0$ ITRFTZ=0 INTRW=0 \&END

PATCH 1 WAKE

$\& W A K E 2$ KWPACH $=1$ KWSIDE $=2 \mathrm{KWLINE}=0 \mathrm{KWPAN} 1=0 \mathrm{KW}-$ $\mathrm{PAN} 2=0 \mathrm{NODEW}=5 \mathrm{INITIAL}=1 \& \mathrm{END}$

$\&$ SECT $1 \quad \mathrm{STX}=20 \quad \mathrm{STY}=0.0 \quad \mathrm{STZ}=0.0 \quad \mathrm{SCALE}=1.0 \quad \mathrm{ALF}=0.0$ $\mathrm{THETA}=0.0 \quad \mathrm{INMODE}=-1 \quad \mathrm{TNODS}=3 \quad \mathrm{TNPS}=20 \quad \mathrm{TINTS}=3$ \&END

$\& O N S T R M$ NONSL $=0$ KPSL $=0 \&$ END

$\&$ BLPARAM $\mathrm{RN}=1000000$. VISC $=0.02304 \mathrm{NSLBL}=0$ \&END

$\& V S 1$ NVOLR $=0$ NVOLC $=0$ \&END

$\&$ SLIN1 NSTLIN $=0$ \&END 